University of Nebraska - Lincoln

DigitalCommons@University of Nebraska - Lincoln

Agronomy \& Horticulture -- Faculty Publications

Agronomy and Horticulture Department

5-10-2004

\title{
Hybrid-maize-a maize simulation model that combines two crop modeling approaches
}

H. S. Yang

University of Nebraska-Lincoln, hyang2@unl.edu

A. Dobermann

University of Nebraska-Lincoln

John L. Lindquist

University of Nebraska-Lincoln, jlindquist1@unl.edu

Daniel T. Walters

University of Nebraska-Lincoln, dwalters1@unl.edu

Timothy J. Arkebauer

University of Nebraska-Lincoln, tarkebauer1@unl.edu

See next page for additional authors

Follow this and additional works at: https://digitalcommons.unl.edu/agronomyfacpub

Part of the Plant Sciences Commons

Yang, H. S.; Dobermann, A.; Lindquist, John L.; Walters, Daniel T.; Arkebauer, Timothy J.; and Cassman, Kenneth G., "Hybrid-maize-a maize simulation model that combines two crop modeling approaches" (2004). Agronomy \& Horticulture -- Faculty Publications. 137.

https://digitalcommons.unl.edu/agronomyfacpub/137

This Article is brought to you for free and open access by the Agronomy and Horticulture Department at DigitalCommons@University of Nebraska - Lincoln. It has been accepted for inclusion in Agronomy \& Horticulture -Faculty Publications by an authorized administrator of DigitalCommons@University of Nebraska - Lincoln. 


\section{Authors}

H. S. Yang, A. Dobermann, John L. Lindquist, Daniel T. Walters, Timothy J. Arkebauer, and Kenneth G. Cassman 
Published in Field Crops Research 87:2-3 (May 10, 2004), pp. 131-154; doi:10.1016/j.fcr.2003.10.003

Copyright (C) 2003 Elsevier B.V. Used by permission. http://www.sciencedirect.com/science/journal/03784290

Submitted July 16, 2003; revised and accepted October 16, 2003; published online January 14, 2004.

\title{
Hybrid-maize - a maize simulation model that combines two crop modeling approaches
}

\author{
H. S. Yang , A. Dobermann, J. L. Lindquist, D. T. Walters, \\ T. J. Arkebauer, and K. G. Cassman* \\ Department of Agronomy and Horticulture, University of Nebraska-Lincoln, \\ P.O. Box 830915, Lincoln, NE 68583-0915, USA \\ ${ }^{*}$ Corresponding author - K. G. Cassman, \\ tel 402 472-1566, fax 402 472-7904, email kcassman1@unl.edu
}

\begin{abstract}
A new maize (Zea mays L.) simulation model, Hybrid-Maize, was developed by combining the strengths of two modeling approaches: the growth and development functions in maize-specific models represented by CERES-Maize, and the mechanistic formulation of photosynthesis and respiration in generic crop models such as INTERCOM and WOFOST. It features temperature-driven maize phenological development, vertical canopy integration of photosynthesis, organ-specific growth respiration, and temperature-sensitive maintenance respiration. The inclusion of gross assimilation, growth respiration and maintenance respiration makes the HybridMaize model potentially more responsive to changes in environmental conditions than models such as CERESMaize. Hybrid-Maize also requires fewer genotype-specific parameters without sacrificing prediction accuracy. A linear relationship between growing degree-days (GDD) from emergence to silking and GDD from emergence to physiological maturity was used for prediction of day of silking when the former is not available. The total GDD is readily available for most commercial maize hybrids. Preliminary field evaluations at two locations under high-yielding growth conditions indicated close agreement between simulated and measured values for leaf area, dry matter accumulation, final grain and stover yields, and harvest index (HI). Key areas for further model improvement include LAI prediction at high plant density, and biomass partitioning, carbohydrate translocation, and maintenance respiration in response to above-average temperature, especially during reproductive growth. The model has not been evaluated under conditions of water and/or nutrient stress, and efforts are currently in progress to develop and validate water and nitrogen balance components for the Hybrid-Maize model.
\end{abstract}

Keywords: crop models, crop simulation, yield potential, Zea mays L

\section{Introduction}

Crop simulation models are mathematical representations of plant growth processes as influenced by interactions among genotype, environment, and crop management. They have become an indispensable tool for supporting scientific research, crop management, and policy analysis (Fischer et al., 2000; Hammer et al., 2002; Hansen,
2002). Simulation models serve different purposes, and the intended purpose influences the level of detail needed for mechanistic description of key processes, sensitivity to environment and management, data requirements, and model outputs. All cereal crop models must simulate plant growth and development, biomass partitioning among organs (leaves, stem, root, and reproductive structures), and yield formation. The accu- 
racy of simulating the outcome of these processes across a wide range of environments depends on basic understanding of the key ecophysiological processes and incorporating this knowledge in the mathematical formulations that constitute the model. For example, accurate prediction of carbon (C) sequestration scenarios in a given cropping system requires robust simulation of grain and stover yields, and the amount of assimilate partitioned belowground to root biomass and exudation (Cassman et al., 2003).

Different approaches have been used for simulating maize (Zea mays L.) development and growth. Generic crop models describe the processes of assimilation, respiration, development and growth without regard to crop species, and are then fine-tuned to simulate the phenological and physiological traits of specific crops such as maize, rice, or potatoes. Examples of generic crop models include SUCROS, WOFOST and INTERCOM (van Ittersum et al., 2003), STICS (Brisson et al., 2003), and CropSyst (Stöckle et al., 2003). In contrast to generic models, other crop models have been developed to simulate growth and development of a specific crop species. The CERES-Maize model and its implementation in DSSAT (Jones and Kiniry, 1986; Jones et al., 2003), and the Muchow-Sinclair-Bennett (MSB) model (Muchow et al., 1990) are examples of maize-specific models.

Maize-specific simulation models differ considerably from generic models in both theoretical framework and treatment of key processes that drive growth and development. For example, INTERCOM (Kropff and van Laar, 1993; Lindquist, 2001) distinguishes only two phases - the vegetative phase from emergence to anthesis and the reproductive phase from anthesis to maturity - and requires input of growing degree-days (GDD) for the duration of both phases. In contrast, CERESMaize distinguishes five development stages emergence to end of juvenile stage, the end of juvenile stage to tassel initiation, tassel initiation to silking, silking to effective grainfilling, and effective grainfilling to physiological maturity - and requires cultivar-specific input parameters for the GDD interval from emergence to the end of the juvenile phase, photoperiod sensitivity, and the duration of silking to maturity in GDD. Two additional cultivar-specific input parameters are required for kernel growth in CERES-Maize.
In generic models such as WOFOST (Van Diepen et al., 1989) and INTERCOM, growth of plant organs is driven primarily by the availability of assimilates from simulation of canopy photosynthesis, and both growth and maintenance respiration are explicitly accounted for to determine dry matter production. In maize-specific models such as MSB and CERES-Maize, growth of organs is primarily driven by temperature, and dry matter production is computed directly from absorbed solar radiation by means of a fixed value for radiation use efficiency (RUE) that accounts for respiration costs implicitly. Use of a fixed RUE value as the driving force of dry matter accumulation in crop simulation models has been questioned because a fixed RUE value incorporates a number of physiological processes, each of which is sensitive to environmental conditions and crop status (Goudriaan and van Laar, 1994; Loomis and Amthor, 1999). Hence, RUE is a dynamic, integrative variable that is sensitive to temperature and light intensity, and models that rely on a fixed RUE value may be less sensitive to variation in climatic conditions and plant physiological status. For example, Edmeades and Bolanos (2001) speculated that the standard RUE value used in CERES-Maize might be too large for tropical regions where high temperatures may result in greater respiration and high peak radiation intensity is conducive to a reduction in photosynthesis from photo-oxidation.

Models such as CERES-Maize (Carberry et al., 1989; Hodges et al., 1987; Kiniry et al., 1997; Liu et al., 1989; Nouna et al., 2000; Pang et al., 1997; Xie et al., 2001) or MSB (Muchow et al., 1990; Wilson et al., 1995) have been validated extensively against field observations in different environments during the past 15 years. However, the maize yields reported in these validation studies are well below maize yield potential, which is defined as the yield of a crop cultivar when grown in environments to which it is adapted, with nutrients and water non-limiting, and pests and diseases effectively controlled (Evans, 1993). Therefore, most of these validations were based on field experiments in which yields were limited by sub-optimal water or nitrogen $(\mathrm{N})$ supply, or other limiting factors. In addition, most of these studies lack detailed measurements of leaf area index (LAI), phenology, crop biomass, or components of yield. These deficiencies preclude a comprehen- 
sive assessment of model performance. To ensure that models are robust in simulating yields across the full range of possible yields, it is important to evaluate model performance under high-yield conditions in which yields approach the yield potential ceiling, as well as in environments that produce lower yield levels under stress.

Recent efforts to improve CERES-Maize have focused on leaf area expansion and senescence (Lizaso et al., 2003a), light capture (Lizaso et al., 2003b), and yield components (Ritchie and Alagarswamy, 2003). Although such improvements may lead to improved simulation of specific processes for selected genotypes and environments, they also require additional cultivar-specific input parameters related to leaf characteristics, change of the light extinction coefficient, or kernel set. Widespread use of these more detailed models would likely be limited by the need for additional cultivar-specific input parameters. Moreover, the short lifespan of modern commercial hybrids makes it difficult to utilize detailed models unless the number of cultivar-specific input parameters is small or the parameters can be easily measured and are accessible to end-users.

The objective of our research was to develop a maize model that can simulate maize yield potential and is sensitive to yield potential variation as influenced by solar radiation and temperature regime. The new model, called "Hybrid-Maize," was developed by combining explicit functions for photosynthesis and respiration used in the assimilate-driven generic crop models INTERCOM and WOFOST with revised CERES-Maize formulations for phenological development and organ growth. The Hybrid-Maize model was then evaluated for its ability to simulate maize leaf area expansion, aboveground dry matter accumulation, grain and stover yields in field experiments in which crop management strived to create growth conditions with minimal possible stress from abiotic and biotic factors. For the purpose of comparison, the field experiments were also simulated using CERES-Maize and INTERCOM.

\section{Field experiments}

\subsection{Lincoln, Nebraska}

A long-term field experiment was established in 1999 at Lincoln, Nebraska (latitude: 40.82N, longitude: $96.65 \mathrm{~W}$, elevation: $357 \mathrm{~m}$ a.s.1.) on a deep Kennebec silt loam (fine-silty, mixed, superactive, mesic Cumulic Hapludoll) (Soil Survey Staff, 1999). The purpose of the experiment was to estimate yield potential of maize and soybean under near-optimal growth conditions, and to better understand the crop and soil management factors that determine yield potential.

The $3 \times 3 \times 2$ factorial experiment was arranged in a split-split plot randomized complete block design with four replicates. Crop rotations (continuous maize, maize-soybean, soybean-maize) were main plot treatments, three levels of plant population density were sub-plot treatments (D1, D2, D3), and two levels of fertilizer-nutrient management were sub-subplot treatments (M1: recommended fertilizer rates, M2: intensive nutrient management). Sub-subplots were $6.1 \mathrm{~m} \times 15.2 \mathrm{~m}$ in size with eight rows at $0.76 \mathrm{~m}$ row spacing. All data presented were obtained in three cropping seasons (1999-2001) from treatments that provided the most favorable growth conditions for high yields: maize grown in rotation with soybean at actual plant densities of 6.97.7 plants $\mathrm{m}^{-2}$ (D1), 8.9-10.2 plants $\mathrm{m}^{-2}$ (D2), and 11.0-11.3 plants $\mathrm{m}^{-2}$ (D3), and the M2 intensive nutrient management regime (Table 1 ).

The crops were irrigated and managed intensively to ensure optimal water and nutrient conditions and avoid stresses from weeds, insects and diseases. The field was deep-ripped in spring 1999 and plowed each year in the fall to create a deep topsoil layer. Average initial soil test values in $0-20 \mathrm{~cm}$ depth were $\mathrm{pH} 5.3,16 \mathrm{~g} \mathrm{C} \mathrm{kg}^{-1}$, $67 \mathrm{mg} \mathrm{kg}^{-1}$ extractable P (Bray-1 method), and $350 \mathrm{mg} \mathrm{kg}^{-1} 1 \mathrm{M} \mathrm{NH}_{4}$-acetate extractable K. Lime was applied in 1999 and 2001 to maintain soil pH at about 6.2. Annual nutrient applications to each maize crop were 225-298 kg N ha-1, $45 \mathrm{~kg} \mathrm{P} \mathrm{ha}^{-1}$, and $85 \mathrm{~kg} \mathrm{~K} \mathrm{ha}^{-1}$. The total $\mathrm{N}$ application amount was adjusted each year to account for residual soil nitrate following the University of Nebraska soil testing guidelines. All $\mathrm{N}$ was applied as ammonium nitrate. A preplant application of 100$105 \mathrm{~kg} \mathrm{~N} \mathrm{ha}^{-1}$ was incorporated before planting and two to three sidedress doses were applied at V6, V10, and VT stages of maize. Field cultivation was performed at V6 stage to incorporate $\mathrm{N}$ fertilizer and control weeds. Blanket doses of $\mathrm{S}, \mathrm{Fe}$, and Zn were applied in 1999 and 2000 and omit- 
Table 1. Maize hybrids, measured plant density, and actual dates of planting, emergence, silking, and physiological maturity at the Lincoln (Nebraska) and Manchester (Iowa) sites

\begin{tabular}{lccccccc}
\hline Site & Year & $\begin{array}{c}\text { Pioneer }{ }^{\circledR} \text { maize } \\
\text { hybrid }\end{array}$ & $\begin{array}{c}\text { Plants } \mathrm{m}^{-2} \\
(\mathrm{D} 1, \mathrm{D} 2, \mathrm{D} 3)\end{array}$ & $\begin{array}{c}\text { Date (DOY) } \\
\text { Planting }\end{array}$ & Emergence & Silking & Maturity \\
\hline Lincoln & 1999 & $33 \mathrm{~A} 14$ & $7.0,8.9,11.3$ & 133 & 141 & 202 & 256 \\
& 2000 & $33 \mathrm{~A} 14$ & $6.9,9.6,11.0$ & 112 & 120 & 188 & 233 \\
\multirow{2}{*}{ Manchester } & 2001 & $33 \mathrm{P} 67$ & $7.7,10.2,11.2$ & 116 & 122 & 191 & 243 \\
& 2002 & $33 P 67$ & 8.4 & 128 & 143 & 203 & 268 \\
\hline
\end{tabular}

ted in 2001 because soil and plant tests indicated adequate supplies of these nutrients. In 1999 and 2000, the experiment was irrigated with a surface drip tape placed beside the plants in each row to fully replenish daily crop evapotranspiration. In 2001, a sub-surface drip irrigation was used with drip tapes placed in alternate rows at a $30 \mathrm{~cm}$ depth. Total amount of irrigation was $255 \mathrm{~mm}$ in 1999 and 2000, and $540 \mathrm{~mm}$ in 2001. Planting dates were 13 May 1999, 21 April 2000, and 26 April 2001. In all 3 years, Bt maize hybrids were used, which minimized the need for insect control with pesticides (Table 1).

\subsection{Manchester, Iowa}

The Manchester, Iowa site (latitude: $42.47 \mathrm{~N}$, longitude: $91.45 \mathrm{~W}$, elevation: $302 \mathrm{~m}$ a.s.l.) is a farm owned by Francis Childs, winner of the National Corn Growers Association yield contest in recent years (NCGA, 2003). The farm does not have access to irrigation. A description of the site and the cropping practices is provided by Murrell and Childs (2000). In 2002, soil, crop, and daily weather data were collected from four contiguous sampling plots located within a $12 \mathrm{~m} \times 150$ m strip of a high-yield field ("Visitor Plot") managed by Mr. Childs, following the same management regime applied in his contest-winning field. The field in which our measurements were taken had been in continuous maize with a high-yield management system for more than 20 years, resulting in a significant build-up of soil organic matter in the top $50 \mathrm{~cm}$ of soil. The soil is a deep, well-drained Kenyon loam (fine-loamy, mixed, superactive, mesic Typic Hapludoll) formed on uplands in loamy sediments and the underlying glacial till. Soil fertility status was high in the top $50 \mathrm{~cm}$ of soil $\left(\mathrm{pH} 5.5,30 \mathrm{~g} \mathrm{C} \mathrm{kg}^{-1}, 105 \mathrm{mg} \mathrm{kg}^{-1}\right.$
Bray-1 P, $320 \mathrm{mg} \mathrm{kg}^{-1} 1 \mathrm{M} \mathrm{NH}_{4}$-acetate extractable $\mathrm{K}$ in $0-30 \mathrm{~cm}$ depth; $\mathrm{pH} 5.8,17 \mathrm{~g} \mathrm{C} \mathrm{kg}^{-1}$, $16 \mathrm{mg} \mathrm{kg}^{-1}$ Bray-1 P, $140 \mathrm{mg} \mathrm{kg}^{-1} 1 \mathrm{M} \mathrm{NH}_{4}$-acetate extractable $\mathrm{K}$ in $30-50 \mathrm{~cm}$ depth).

Maize hybrid Pioneer ${ }^{\circledR} 33$ P67 was planted on 8 May 2002 with a row spacing of $0.51 \mathrm{~m}$ and a final plant density of 8.4 plants $\mathrm{m}^{-2}$. A total of $455 \mathrm{~kg} \mathrm{~N} \mathrm{ha}^{-1}$ was applied, with $56 \mathrm{~kg} \mathrm{~N} \mathrm{ha}^{-1}$

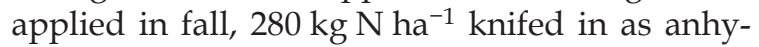
drous ammonia before planting, $7 \mathrm{~kg} \mathrm{~N} \mathrm{ha}^{-1}$ applied as liquid starter fertilizer at planting, and $112 \mathrm{~kg} \mathrm{~N} \mathrm{ha}^{-1} \mathrm{~N}$ applied as urea-ammonium nitrate solution shortly after planting. Other nutrient applications included $7.5 \mathrm{~kg} \mathrm{Pha}^{-1}$ and $23 \mathrm{~kg} \mathrm{~K} \mathrm{ha}^{-1}$ and various micronutrients ( $\mathrm{Zn}, \mathrm{Fe}$, $\mathrm{Mn}, \mathrm{B}, \mathrm{Mo})$ with starter fertilizers. Rainfall was well-distributed throughout the growing season such that crop moisture stress was avoided.

\subsection{Measurements}

Automatic weather stations located at both field sites provided daily climate data throughout the growing season (Table 2). Plant measurements included the date of major phenological events, aboveground biomass, biomass partitioning (stems, green leaves, dead leaves, reproductive biomass), and LAI at 5 (Manchester) or 7-15 (Lincoln) growth stages. At each sampling time, five consecutive plants were clipped at the soil surface at random locations within each treatment plot at Lincoln and in each of the sampling plots at Manchester.

At physiological maturity (R6 stage), a 6-plant sample was collected from a designated harvest area of $13.9 \mathrm{~m}^{2}$ (2 rows $\left.\times 9.12 \mathrm{~m}\right)$ within each plot to obtain final estimates of biomass partitioning (grain, cobs, stems+leaves) and harvest index (HI). The number of plants, ears, and 
Table 2. Total solar radiation, and average daily maximum $\left(T_{\max }\right)$ and minimum $\left(T_{\min }\right)$ temperature during the growing season at Lincoln (Nebraska) and Manchester (Iowa)

\begin{tabular}{|c|c|c|c|c|c|c|c|c|c|c|}
\hline \multirow[t]{2}{*}{ Site } & \multirow[t]{2}{*}{ Year } & \multicolumn{3}{|c|}{ Whole season } & \multicolumn{3}{|c|}{ Emergence to silking } & \multicolumn{3}{|c|}{ Silking to maturity } \\
\hline & & $\overline{\text { Days }}$ & $\begin{array}{r}\text { Radiation } \\
\left(\mathrm{MJ} \mathrm{m}^{-2}\right)\end{array}$ & $\overline{T_{\text {max }} T_{\left({ }^{\prime} \mathrm{C}\right)} T_{\min }}$ & $\overline{\text { Days }}$ & $\begin{array}{l}\text { Radiation } \\
\left(\mathrm{MJ} \mathrm{m}^{-2}\right)\end{array}$ & $\overline{\left.T_{\max }{ }^{\circ} \mathrm{C}\right)}$ & $\overline{\text { Days }}$ & $\begin{array}{r}\text { Radiation } \\
\left(\mathrm{MJ} \mathrm{m}^{-2}\right)\end{array}$ & $T_{\left.{ }_{\max }{ }^{\circ} \mathrm{C}\right)} T_{\text {min }}$ \\
\hline \multirow[t]{4}{*}{ Lincoln } & 1999 & 115 & 2249 & $28.7,17.6$ & 61 & 1174 & $27.4,16.6$ & 54 & 1075 & $30.1,18.6$ \\
\hline & 2000 & 113 & 2565 & $29.0,16.7$ & 68 & 1540 & $27.7,14.3$ & 45 & 1025 & $30.8,20.0$ \\
\hline & 2001 & 121 & 2574 & $28.6,17.2$ & 69 & 1451 & $26.5,14.8$ & 52 & 1123 & $31.4,20.4$ \\
\hline & \multicolumn{2}{|c|}{ Long-term mean ${ }^{a}$} & 2405 & $28.9,17.1$ & & 1419 & $27.7,15.8$ & & 986 & $30.4,18.9$ \\
\hline Manchester & 2002 & 125 & 2552 & $27.6,15.2$ & 60 & 1341 & $27.3,16.6$ & 65 & 1211 & $27.4,13.6$ \\
\hline
\end{tabular}

a 17-Year means (1986-2002) for the whole season, emergence to silking, and silking to maturity based on the mean dates of emergence, silking and maturity in the three cropping seasons in 1999, 2000, and 2001 at Lincoln.

barren stalks were counted within the entire harvest area, and ears were handpicked to determine grain yield when grain moisture fell below $250 \mathrm{~g} \mathrm{~kg}^{-1}$. Kernels were separated from cobs, and plant samples were oven-dried to constant weight at $70^{\circ} \mathrm{C}$. All yields are reported on an oven-dry basis. Stover (stems+leaves) and cob dry matter yields were calculated from the grain yield measured in the designated harvest areas and the HI and cob HI obtained from the 6-plant sample collected at the R6 stage.

\section{Development of the Hybrid-Maize model}

The purpose of the Hybrid-Maize model is to accurately predict yield of maize as determined by solar radiation, temperature, phenology, and canopy architecture, when grown under favorable conditions that minimize stress and allow yields to approach yield potential levels. The model includes formulations from CERES-Maize for phenological development and organ growth (Jones and Kiniry, 1986; Kiniry et al., 1997), and functions for photosynthesis and respiration as found in INTERCOM (Kropff and van Laar, 1993) and Goudriaan and van Laar (1994) (Table 3). The modified and new components in Hybrid-Maize that differ from CERES-Maize or INTERCOM are discussed below. Default values of user-modifiable parameters in Hybrid-Maize are listed in Appendix A. Because the functions for crop growth and development in Hybrid-Maize were largely adapted from CERES-Maize, the base temperature of $8^{\circ} \mathrm{C}$ in CERES-Maize was retained in Hybrid-Maize for GDD-related internal parameters and variables. For user-input parameters related to GDD, a base temperature of $10^{\circ} \mathrm{C}$ is used because most GDD-related crop parameters provided by seed companies are based on this temperature.

Hybrid-Maize is available as a Windowsbased PC software with full text and graphical display that allows export of simulation results. The software converts climate data from the High Plains Regional Climate Center (http:// www.hprcc.unl.edu) into the format required by the model. It also provides users access to all key model parameters for viewing or editing (Appendix A), as well as the possibility of restoring the original default values of those parameters. The model can be run in single-season mode as well as for long-term simulations using multi-year climate data at a given site. Model source code is available upon request from the senior author (hyang2@unl.edu).

\subsection{Light interception and photosynthesis}

In CERES-Maize, it is assumed that $50 \%$ of the total incident solar radiation $(I)$ is photosynthetically active radiation (PAR). The amount of intercepted PAR (PAR $)_{i}$ by the plant canopy is computed by the exponential function:

$$
\mathrm{PAR}_{\mathrm{i}}=0.5 I\left(1-\mathrm{e}^{-k \mathrm{LAI}}\right)
$$

and net dry matter production is computed by means of RUE:

$$
\mathrm{DM}=\mathrm{PAR}_{\mathrm{i}} \times \mathrm{RUE}
$$

where $I$ is the incoming total solar radiation 


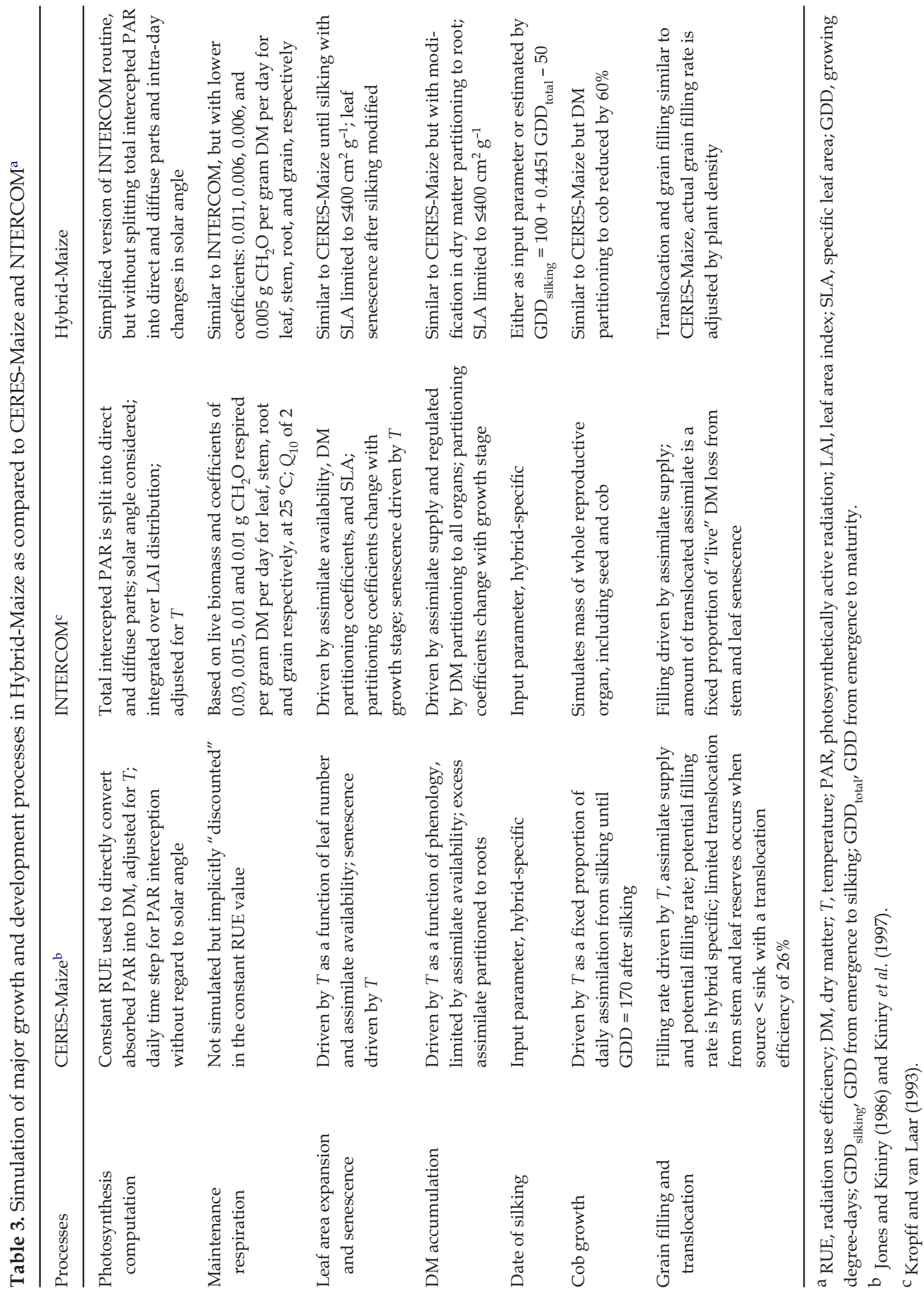


(MJ m ${ }^{-2}$ per day), $k$ the light extinction coefficient ( $=0.65$ in the original version of CERES-Maize, based on Monteith (1969)), LAI the leaf area index ( $\mathrm{m}^{2}$ leaf $\mathrm{m}^{-2}$ ground), and DM the total amount of crop dry matter produced $\left(\mathrm{g} \mathrm{m}^{-2}\right.$ ground per day). The value of RUE was set at $5 \mathrm{~g} \mathrm{MJ}^{-1}$ PAR in the first version of CERES-Maize (Jones and Kiniry, 1986), but reduced to $4.33 \mathrm{~g} \mathrm{MJ}^{-1}$ PAR in a later version (Kiniry et al., 1997). The $4.33 \mathrm{~g} \mathrm{MJ}^{-1}$ PAR value was used in the CERES-Maize simulations reported here.

In Hybrid-Maize, PAR $_{\mathrm{i}}$ and gross assimilation are described according to formulations in INTERCOM and WOFOST. The PAR $\mathrm{P}_{\mathrm{i}}$ and its corresponding $\mathrm{CO}_{2}$ assimilation are computed for each layer in the canopy. Total gross assimilation is then obtained by integration over all layers. Using $L$ to represent the depth of canopy with $L=0$ at the top and $L=$ LAI at the bottom of the canopy, the $\mathrm{PAR}_{\mathrm{i}}$ at position $L$ in the canopy equals the decrease of PAR at that depth. Differentiation of Equation (1) yields:

$$
\mathrm{PAR}_{\mathrm{i}, \mathrm{L}}=\mathrm{dPAR} / \mathrm{d} L=0.5 I k \mathrm{e}^{-k L}
$$

where $\mathrm{PAR}_{\mathrm{i}, L}$ is the PAR interception by the canopy layer at position $L$. The corresponding $\mathrm{CO}_{2}$ assimilation by that layer follows a saturation function of the form:

$$
A_{L}=A_{\mathrm{m}}\left(1-\mathrm{e}^{-\varepsilon P A R_{\mathrm{i}, L} / A_{\mathrm{m}}}\right)
$$

where $A_{L}$ is the $\mathrm{CO}_{2}$ assimilation by the canopy layer at $L, A_{\mathrm{m}}$ the maximum gross $\mathrm{CO}_{2}$ assimilation rate $\left(\mathrm{g} \mathrm{CH}_{2} \mathrm{O} \mathrm{m}^{-2}\right.$ leaf $\left.\mathrm{h}^{-1}\right)$, and $\varepsilon$ the initial light use efficiency ( $\left.\mathrm{g} \mathrm{CO}_{2} \mathrm{MJ}^{-1} \mathrm{PAR}\right)$. The $\mathrm{CO}_{2}$ assimilation by the whole canopy is obtained by integration of Equation (4) along L:

$$
A=\int_{L=0}^{\mathrm{LAI}} A_{\mathrm{m}}\left(1-\mathrm{e}^{-\varepsilon \mathrm{PAR}_{\mathrm{i}, L} / A_{\mathrm{m}}}\right) \mathrm{d} L
$$

where $A$ is the gross $\mathrm{CO}_{2}$ assimilation of the canopy $\left(\mathrm{g} \mathrm{CO}_{2} \mathrm{~m}^{-2}\right.$ ground $\left.\mathrm{h}^{-1}\right)$. Two numerical integration methods are available in the model. The default method, which was used in all the simulations of this study is the three-point Gaussian method (Goudriaan, 1986). Alternatively, a user can choose the standard Simpson's rule with a user-defined precision. A $k$ value of 0.55 is used in Hybrid-Maize based on data from Lizaso et al. (2003b), Maddonni et al. (2001), and our measurements made in the field experiment at Lincoln
(J.L. Lindquist, unpublished data). The values of $\varepsilon$ $=12.5 \mathrm{~g} \mathrm{CO}_{2} \mathrm{MJ}^{-1}$ PAR, $A_{\mathrm{m}}=7 \mathrm{~g} \mathrm{CO}_{2} \mathrm{~m}^{-2}$ leaf $\mathrm{h}^{-1}$, and the relationship of $A_{\mathrm{m}}$ with temperature were adapted from Kropff and van Laar (1993). Unlike INTERCOM, Hybrid-Maize computes the gross assimilation in a daily time step without differentiating incident radiation into diffuse and direct components.

\subsection{Maintenance and growth respiration}

CERES-Maize uses RUE to convert PAR directly into dry matter production and, therefore, does not explicitly account for growth or maintenance respiration. Hybrid-Maize utilizes formulations for maintenance and growth respiration similar to those in INTERCOM, and the coefficients of growth respiration for leaf, stem, root and grain (Table 3) were adopted from Penning de Vries et al. (1989), as used by Kropff and van Laar (1993). Similar to INTERCOM and WOFOST, Hybrid-Maize assumes that the entire mass of each organ respires before silking, but only the "live" biomass thereafter. The fraction of "live" biomass after silking is set to be equal to the ratio of LAI at any point during grain filling to the maximum LAI, which occurs at silking (Kropff and van Laar, 1993). Maintenance respiration of each organ is then estimated on a daily time step as a fraction of live biomass.

The coefficients for maintenance respiration (MRC) used in generic crop models such as INTERCOM were derived nearly two decades ago, based on a combination of theoretical considerations, experimental measurements, and model studies (Penning de Vries et al., 1989; van Ittersum et al., 2003). These coefficients may be too large for modern maize hybrids. Earl and Tollenaar (1998) showed that more recent maize hybrids had smaller respiration losses than older hybrids. Therefore, the MRC coefficients for maintenance respiration in Hybrid-Maize were obtained by calibrating model prediction of dry matter yields against the observed yields from the field experiment conducted in 1999 at Lincoln (Table 3). No other experimental data were used for this calibration. Smaller MRC coefficients than those used in generic crop models such as INTERCOM greatly improved the accuracy of predicting dry matter accumulation. Moreover, the mean of the MRC obtained from this calibration $\left(0.007 \mathrm{~g} \mathrm{~g}^{-1}\right.$ 
per day) was comparable to the whole-plant respiration value of $0.008 \mathrm{~g} \mathrm{~g}^{-1}$ per day at silking reported by Kiniry et al. (1992).

\subsection{Leaf growth and senescence}

In CERES-Maize, temperature drives leaf area expansion, which in turn drives leaf biomass growth as follows:

$$
\mathrm{LW}=(\mathrm{PLA} / 267)^{1.25}
$$

where LW is the total leaf biomass (g per plant), and PLA the total plant leaf area ( $\mathrm{cm}^{2}$ per plant). According to Equation (6), the specific leaf area (SLA) will exceed $400 \mathrm{~cm}^{2} \mathrm{~g}^{-1}$ at PLA of $50 \mathrm{~cm}^{2}$ per plant, and exceed $300 \mathrm{~cm}^{2} \mathrm{~g}^{-1}$ at PLA of $165 \mathrm{~cm}^{2}$ per plant. However, in the field experiments at Lincoln with maize grown under optimal conditions, SLA never exceeded $300 \mathrm{~cm}^{2} \mathrm{~g}^{-1}$ (J.L. Lindquist, unpublished data), which is also in agreement with the observations of Kropff et al. (1984). This suggests that CERES-Maize may under-predict leaf biomass growth during the early vegetative stage. Therefore, a limit of SLA $\leq 400 \mathrm{~cm}^{2} \mathrm{~g}^{-1}$ was set in Hybrid-Maize when estimating leaf biomass growth from leaf area expansion, and SLA was computed at the end of each day as:

$$
\mathrm{SLA}=\mathrm{LW} / \mathrm{PLA}
$$

In CERES-Maize, leaf area expansion ceases at silking, which is the point of maximum LAI, and leaf senescence proceeds thereafter in two phases. The first phase, from start of silking to beginning of effective grain filling, lasts for 170 GDD and follows:

$$
\mathrm{SLAN}=\mathrm{PLA}_{\text {silking }} \times 0.05(1+\operatorname{sumDTT} / 170)
$$

where SLAN denotes the total senescent leaf area $\left(\mathrm{cm}^{2}\right.$ per plant), $\mathrm{PLA}_{\text {silking }}$ the total leaf area at silking ( $\mathrm{cm}^{2}$ per plant), sumDTT the cumulative GDD from the start of silking. The second phase proceeds from the beginning of effective grain filling until maturity according to:

$$
\text { SLAN }=\text { PLA }_{\text {silking }}\left(0.1+.08\left(\operatorname{sumDTT} / P_{5}\right)^{3}\right)
$$

where $P_{5}$ is the GDD from silking to maturity.
The SLAN estimated by Equations (8) and (9) is then compared with the total leaf senescence that would occur from low light intensity (i.e. lack of light in the bottom layers of the canopy) and low temperature, as estimated by specific formulations for these effects, and the smaller of the two estimates is then taken as the actual leaf senescence. The drawbacks of this approach are the abrupt decreases in LAI at the onset of silking and at the transition from linear senescence (Equation (8)) to rapidly accelerated leaf senescence thereafter (Equation (9)) - patterns that are not observed in the field.

In Hybrid-Maize, the two phases of leaf senescence were combined into one function for leaf senescence for the whole period from start of silking to maturity:

$$
\mathrm{SF}=0.7\left(\operatorname{sumDTT} / P_{5}\right)^{4}
$$

in which SF denotes the senescent leaf area as a fraction of LAI at silking. The sumDTT is calculated as:

$$
\text { sumDTT }=(\text { sumDTT }+ \text { DTT }) \div(1-\text { LSR })
$$

in which DTT denotes the daily effective temperature, LSR the stress rate caused by low temperature and competition for light ( 0 to 1 , with 1 for stress free and 0 for full stress, as in CERESMaize). In Equation (10), the exponent, or staygreen coefficient, determines the speed of leaf senescence while the coefficient 0.7 determines the final amount of senescent LAI as a fraction of maximum LAI at silking. Both parameters are related to the "stay-green" trait of maize hybrids as well as G×E interactions that influence leaf senescence, especially with regard to plant $\mathrm{N}$ status and water relations (Fakorede and Mock, 1980; Rajcan and Tollenaar, 1999). Although commercial seed companies typically provide scores for the stay-green trait, the scale differs among individual companies because the scores are not based on a standardized scale. While the current version of Hybrid-Maize, as used in this study, treats the exponent and coefficient in Equation (10) as constants, it would be possible to treat them as dynamic variables responsive to $\mathrm{N}$ and water stress, or as hybrid-specific input parameters. 


\subsection{Development stages and occurrence of silking}

In CERES-Maize, aboveground phenological development is divided into five stages marked by six indicators: emergence, end of juvenile phase, tassel initiation, silking, start of effective grain filling, and physiological maturity. The duration of the first stage (from emergence to end of juvenile phase) is determined by the input parameter $P_{1}$, which is the GDD requirement for this growth period. The duration of the second stage (from end of juvenile phase to tassel initiation) is a function of the input parameter $P_{2}$, or the photoperiod sensitivity, and the latitude of the field site. The functions governing plant growth and development are the same in stage- 1 and stage- 2 . The duration of stage- 3 (from tassel initiation to silking) is a proportional function of the accumulated GDD of the first two stages. The duration of stage-4 (from silking to the start of effective grain filling) is fixed at GDD $=170$, and the duration of the fifth and final stage is determined by the input parameter $P_{5}$, which is the GDD from silking to maturity.

Occurrence of silking has a large influence on simulated grain yield through the effect on length of grain filling. In CERES-Maize, silking is determined by the input parameters $P_{1}$ and $P_{2}$. It is difficult, however, to estimate the value of $P_{1}$ under field conditions (Edmeades and Bolanos, 2001), and $P_{1}$ is not readily available for most commercial hybrids grown in different environments. Moreover, it is not known if $P_{1}$ is a constant for hybrids with similar maturity, or if it is sensitive to environmental conditions other than temperature. This uncertainty makes the selection of an appropriate $P_{1}$ difficult, which could result in inaccurate prediction of silking (Roman et al., 2000). Overall, CERES-Maize requires input of three hybrid-specific input parameters $\left(P_{1}, P_{2^{\prime}}\right.$ and $P_{5}$ ) to simulate aboveground phenological development.

In contrast, Hybrid-Maize requires only one hybrid-specific parameter to simulate aboveground phenological development as defined by tassel initiation, silking, grain filling and physiological maturity. Occurrence of silking is determined in one of two ways: (1) by user input of GDD from emergence to silking $\left(\mathrm{GDD}_{\text {silking }}\right.$ base $T=10^{\circ} \mathrm{C}$ ), or (2) by user input of total GDD from emergence to maturity $\left(\mathrm{GDD}_{\text {total }}\right.$, base $T=$ $10^{\circ} \mathrm{C}$ ). Many seed companies typically publish $\mathrm{GDD}_{\text {silking }}$ or $\mathrm{GDD}_{\text {total }}$ values for their commercial hybrids, which means that one or both parameters are generally available. In some cases, however, only one of these two parameters is available. In such cases, Hybrid-Maize estimates either $\mathrm{GDD}_{\text {silking }}$ or $\mathrm{GDD}_{\text {total }}$ from the following relationship (Figure 1):

$$
\mathrm{GDD}_{\text {silking }}=100+0.445 \mathrm{GDD}_{\text {total }}
$$

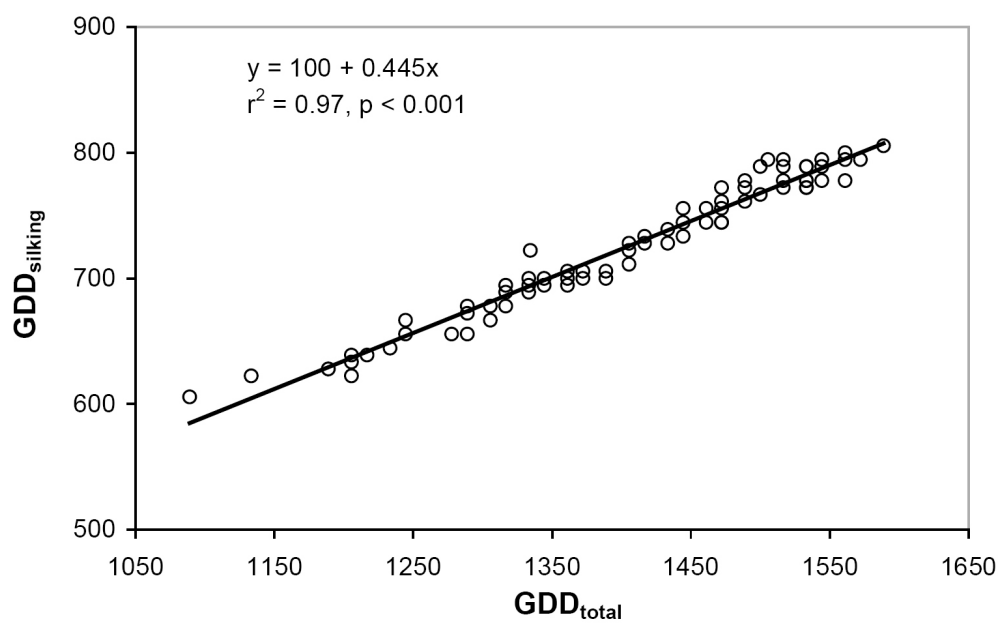

Figure 1. Regression of GDD (base $T=10^{\circ} \mathrm{C}$ ) from emergence to silking (GDD $\mathrm{Gilking}_{\text {) }}$ ) on total GDD from emergence to physiological maturity $\left(\mathrm{GDD}_{\text {total }}\right)$ for 107 commercial maize hybrids. Values are based on Pioneer ${ }^{\circledR} \mathrm{Hi}$ Bred International, Inc. Crop Notes 2001-2002. Many points have the same values and thus overlap. 
This relationship was derived from published values of $\mathrm{GDD}_{\text {silking }}$ and $\mathrm{GDD}_{\text {total }}$ for $107 \mathrm{com}$ mercial maize hybrids that are widely used in the north-central USA (Pioneer Hi-Bred, 2001). However, in Hybrid-Maize, an additional offset of -50 was applied to the intercept in Equation (12) to provide a more accurate prediction of silking under optimal water conditions. This offset was included because the data sets used to obtain the relationship in Equation (12) came from thousands of field trials conducted under a wide range of growth conditions that included both irrigated and rainfed environments. Under such widespread testing, some of the rainfed sites experience a water deficit, which delays silking (Saini and Westgate, 2000). Therefore, the GDD silking under optimal irrigated conditions would likely be smaller than the average of values of the data sets obtained from widespread testing.

After establishing $\mathrm{GDD}_{\text {silking' }}$ the occurrence of tassel initiation in Hybrid-Maize is then determined by an iterative process from CERES-Maize that utilizes a proportional function relating the duration from tassel initiation to silking to the duration of the first two development stages.

\subsection{Cob growth and grain filling}

In CERES-Maize, cob growth is initiated at silking with initial biomass set to equal $17 \%$ of total stem biomass, and cob growth ceases at the end of stage- 4 when effective grain filling begins. When calibrated against measurements in the Lincoln field study, however, the predicted cob biomass was double the measured values. Therefore, in Hybrid-Maize, the daily dry matter allocation to cob was reduced by $60 \%$ compared to CERES-Maize.

The daily grain-filling rate in CERES-Maize is the product of the potential grain-filling rate $\left(G_{5}\right)$ and the grain filling efficiency, which is driven by temperature but is independent of plant density. As a result, simulated weight of individual grains is constant across large differences in plant density. Typically, individual grain weight decreases in cereal crops as plant density increases, especially at high plant populations. Using 1999 and 2000 data from the three plant density treatments at Lincoln, the following empirical relationship was derived and used in Hybrid-Maize to reduce the rate of grain filling at increased plant densities:

$F=1.47-0.09 D+0.0036 D^{2}, \quad r^{2}=0.78, P<0.01$

where $F$ denotes the factor for adjusting grain filling rate based on plant population $\left(D\right.$, plant $\left.\mathrm{m}^{-2}\right)$. Because Equation (13) was derived for a range of 6.9-11.3 plants $\mathrm{m}^{-2}$, the value of $F$ was limited to $\geq 0.89$ and $\leq 1.0$ in the model. While plant densities for irrigated maize typically fall within this range, the relationship in Equation (13) has not been validated at higher or lower densities and therefore the model should not be used outside this range.

\subsection{Root biomass}

In CERES-Maize, root growth is divided into the three stages from stage- 1 to stage-3, and stops at end of stage-3. Each of these stages has a minimum dry matter partitioning fraction to roots: $0.25,0.1$ and 0.08 for stage- 1 , stage- 2 and stage- 3 , respectively. Any dry matter in excess of growth requirements for leaves and stems is partitioned to roots on a daily time step. In addition, half of the gross gain of dry matter allocation to roots is lost to respiration, and $0.5 \%$ of the total root biomass is lost via root senescence-both on a daily time step.

In Hybrid-Maize, a continuous function derived from the data for maize in Kropff and van Laar (1993), was used to determine the minimum fraction of dry matter partitioning to roots $\left(\mathrm{RF}_{\min }\right)$ :

$$
\mathrm{RF}_{\text {min }}=0.35-\frac{0.35 \mathrm{GDD}}{1.15 \mathrm{GDD}_{\text {silking }}}, \quad \mathrm{RF} \geq 0
$$

where GDD denotes the growing degree-day accumulation from emergence. If there is dry matter remaining after meeting the growth requirements for leaf and stem and $\mathrm{RF}_{\mathrm{min}^{\prime}}$ the dry matter fraction partitioned to roots is increased to an upper limit of 0.5 of daily net assimilation. Moreover, all the dry matter gain in root is treated as a net gain in plant dry matter because respiration is already accounted for in the estimation of net assimilation. Allocation of dry matter to roots ceases when GDD reaches $115 \%$ of $\mathrm{GDD}_{\text {silk- }}$ ing. Similar to CERES-maize, $0.5 \%$ of the root biomass is lost to fine-root turnover or senescence on a daily basis. 


\subsection{Model evaluation and sensitivity analysis}

The performance of Hybrid-Maize was evaluated for all 10 data sets listed in Table 1, including nine year $\times$ plant density treatment combinations at Lincoln and the 2002 growing season at Manchester. All simulations were initiated from emergence, and the actual GDD total $_{\text {of the }}$ four cropping seasons was used as an input parameter such that simulations terminated on the dates of observed physiological maturity (Table 1). Measured plant densities were also used, and silking was predicted for each growing season

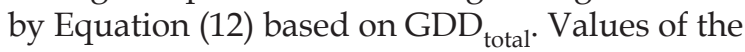
other key parameters in Hybrid-Maize are given in Appendix A.

The 10 data sets were also simulated with CERES-Maize (1995 version provided by J. Kiniry) and INTERCOM (Lindquist, 2001). For CERESMaize, each simulation was initiated from the date of sowing and the sowing depth was adjusted so that the predicted date of emergence matched the observed date. Parameters $G_{2}$ and $G_{5}$ were set the same as the values used in $\mathrm{Hy}$ brid-Maize (Appendix A). For each run, $P_{5}$ was set so that the simulation ended on the date of observed maturity. For Lincoln 1999 and 2000 and Manchester, $P_{1}$ was set at 220 , which is the mean $P_{1}$ value for northern and southern $\mathrm{Ne}$ braska, Iowa, Illinois, and Indiana (Jones and Kiniry, 1986). For Lincoln 2001, $P_{1}$ was set at 250 because the observed date of maturity could not be reached even when $P_{5}$ was set at 999 (the highest value the CERES-Maize program accepts). For INTERCOM, all runs started from the date of observed emergence. Development rates for vegetative and reproductive stages were input parameters based on the inverse of actual GDD (base T $=10^{\circ} \mathrm{C}$ ) in each season from emergence to silking and from silking to maturity, respectively. Because INTERCOM does not simulate cob and grain growth separately, grain yield was estimated to be $87 \%$ of the total ear biomass based on grain to ear mass ratio measured in the Lincoln experiment. For both CERES-Maize and INTERCOM, simulations were performed with settings for optimal water and nutrient supply.

The degree of agreement between simulated and measured values for LAI and dry matter accumulation were assessed in two ways. The first plots the absolute value of the difference between predicted and measured values for LAI and dry matter accumulation versus the day after emergence when the measurements were made to examine whether the models have a particular bias during specific growth stages. The second quantifies the deviations between predicted and measured values by estimating the modeling efficiency (EF) and absolute modeling error (AE), as computed by (Smith et al., 1997):

$$
\mathrm{EF}=1-\frac{\sum_{i=1}^{n}\left(P_{i}-O_{i}\right)^{2}}{\sum_{i=1}^{n}\left(O_{i}-\bar{O}\right)^{2}}
$$

where $O_{i}$ denotes measured values, $\bar{O}$ the mean of $O_{i}, P_{i}$ the predicted values, and $n$ the number of measurements. As EF is similar to $r^{2}$ in regression analysis, $\mathrm{EF}=1$ indicates perfect agreement of model predictions with the direct measurements of the parameter in question, and $\mathrm{EF}=0$ or a negative EF indicates that $\bar{O}$ is a better predictor than the model. Absolute error (AE) is an indicator of the mean bias in the total difference between simulated values and measurements:

$$
\mathrm{AE}=\frac{1}{n} \sum_{i=1}^{n}\left(P_{i}-O_{i}\right)
$$

Hence, $\mathrm{AE}<0$ indicates under-prediction and $\mathrm{AE}>0$ indicates over-prediction. The AE corresponding to the $95 \%$ confidence interval of the two-tailed $t$-test $\left(\mathrm{AE}_{95 \%}\right)$ was computed by:

$$
\mathrm{AE}_{95 \%}=\frac{1}{n} \sum_{i=1}^{n}\left(t_{(n-2) 95 \%} \times \text { S.E. }\right)
$$

where $t_{(n-2) 95 \%}$ denotes the two-tailed $t$ at $95 \%$ interval with d.f. $=n-2$, and S.E. is the standard error of the mean. The AE becomes significant if $>\mathrm{AE}_{95 \%}$. Because fewer dry matter measurements were taken after silking when dry matter values and associated simulation errors are much larger than in the vegetative stage, the $\mathrm{EF}$ and $\mathrm{AE}$ values should be interpreted with caution.

The Hybrid-Maize model was also tested for the sensitivity of maize yield potential to selected parameters from Appendix A using 17 years of weather data (1986-2002) at Lincoln. The following parameters were evaluated: the two hybridspecific coefficients related to kernel set and grain filling $\left(G_{2}\right.$ and $\left.G_{5}\right)$, light extinction coefficient $(k)$, translocation efficiency (TE) of carbohydrate for grain filling, initial light use efficiency $(\varepsilon)$, MRC of leaf, stem, root and grain, and occurrence of 
silking. Except for the occurrence of silking, the changes in each parameter were $\pm 10 \%, \pm 20 \%$, and $\pm 30 \%$ of the values listed in Appendix A. Silking occurrence was changed $\pm 2, \pm 5$, and \pm 10 days by invoking the option of using different values of the input parameter $\mathrm{GDD}_{\text {silking' }}$ while keeping $\mathrm{GDD}_{\text {total }}$ constant at 1500, which is comparable to the maturity of the two hybrids used in the Lincoln study. Other common settings were: sowing on 1 May, plant density $=10$ plants $\mathrm{m}^{-2}$, and sowing depth $=3.5 \mathrm{~cm}$.

\section{Results}

\subsection{Simulation of maize growth dynamics with min- imal stress}

Climatic conditions in the 2000 and 2001 growing seasons at Lincoln differed substantially from those in 1999 (Table 2). The crop was sown later in 1999 than in 2000 and 2001 so that vegetative growth was reduced and grain filling occurred in late August and early September in 1999, when the minimum (night) temperature seldom exceeded $21^{\circ} \mathrm{C}$. In contrast, earlier planting in both 2000 and 2001 and relatively hot and dry periods in July and August caused grain filling to oc- cur with mean minimum air temperature exceeding that of 1999 by $1.4-1.8^{\circ} \mathrm{C}$. Consequently, the grain filling periods in 2000 and 2001 were 9 and 2 days shorter than in 1999, respectively. At Manchester, cumulative solar radiation during the entire growing season was similar to that of 1999 and 2000 at Lincoln, but crop maturity occurred later due to a much longer grain filling period (65 days). The longer grain filling period at Manchester was associated with a mean maximum temperature that was $3-4{ }^{\circ} \mathrm{C}$ cooler than that at Lincoln, while mean minimum temperature was $5-7^{\circ} \mathrm{C}$ cooler during grain filling.

Simulated LAI by all three models was in close agreement with observed values for the first 30 or 40 days after emergence (Figure 2, Figure 3, and Figure 4). At later development stages, simulated LAI values were more accurate at low plant density than at high plant density, but all models tended to under-predict maximum LAI during mid-season (Figure 3), particularly when measured LAI was $>6$. LAI remained near maximum levels for about 40 days after silking, which indicates active canopy assimilation during grain filling and lack of stress from inadequate water or $\mathrm{N}$ supply. Overall, predictions of LAI dynamics by Hybrid-Maize were closer

Table 4. Modeling efficiency and absolute error of predicting the time course of LAI and aboveground dry matter accumulation (AG biomass) ${ }^{\mathrm{a}}$

\begin{tabular}{|c|c|c|c|c|}
\hline \multirow[t]{2}{*}{ Model (site-year) } & \multicolumn{2}{|c|}{ Modeling efficiency (EF) } & \multicolumn{2}{|c|}{ Absolute error $(\mathrm{AE})^{\mathrm{b}}$} \\
\hline & $\overline{\mathrm{LAI}}$ & AG biomass & LAI & AG biomass $\left(\mathrm{Mg} \mathrm{ha}^{-1}\right)$ \\
\hline \multicolumn{5}{|l|}{ Hybrid-Maize } \\
\hline Lincoln 1999 & 0.93 & 0.99 & $0.22 n s$ & $0.27 n s$ \\
\hline Lincoln 2000 & 0.88 & 0.97 & $-0.32 n s$ & $0.50 \mathrm{~ns}$ \\
\hline Lincoln 2001 & 0.90 & 0.98 & $-0.56 \mathrm{c}$ & $-0.27 n s$ \\
\hline Manchester 2002 & 0.90 & 1.00 & $-0.42 n s$ & $-0.09 n s$ \\
\hline \multicolumn{5}{|l|}{ CERES-Maize } \\
\hline Lincoln 1999 & 0.90 & 0.95 & $0.08 n s$ & $-0.38 n s$ \\
\hline Lincoln 2000 & 0.69 & 0.97 & $-0.76^{c}$ & $-0.27 n s$ \\
\hline Lincoln 2001 & 0.63 & 0.95 & $-1.16^{c}$ & $-0.87 n s$ \\
\hline Manchester 2002 & 0.82 & 0.98 & $-0.67 \mathrm{c}$ & $-0.99 n s$ \\
\hline \multicolumn{5}{|l|}{ INTERCOM } \\
\hline Lincoln 1999 & 0.71 & 0.87 & $-0.67 \mathrm{c}$ & $-1.26 n s$ \\
\hline Lincoln 2000 & 0.90 & 0.95 & $-0.34 n s$ & $-0.46 n s$ \\
\hline Lincoln 2001 & 0.50 & 0.80 & $-1.52^{c}$ & $-2.92^{c}$ \\
\hline Manchester 2002 & 0.43 & 0.89 & $-1.54^{\mathrm{c}}$ & $-2.41^{\mathrm{c}}$ \\
\hline
\end{tabular}

a Values for Lincoln 1999-2001 are based on observations from the three plant density treatments.

$\mathrm{b} n$ s indicates an AE value smaller than the $95 \%$ confidence interval in two-tailed t-test with d.f. $=\mathrm{n}-2$.

c Indicates an AE value corresponding to a 95\% confidence interval in two-tailed t-test with d.f. $=\mathrm{n}-2$. 


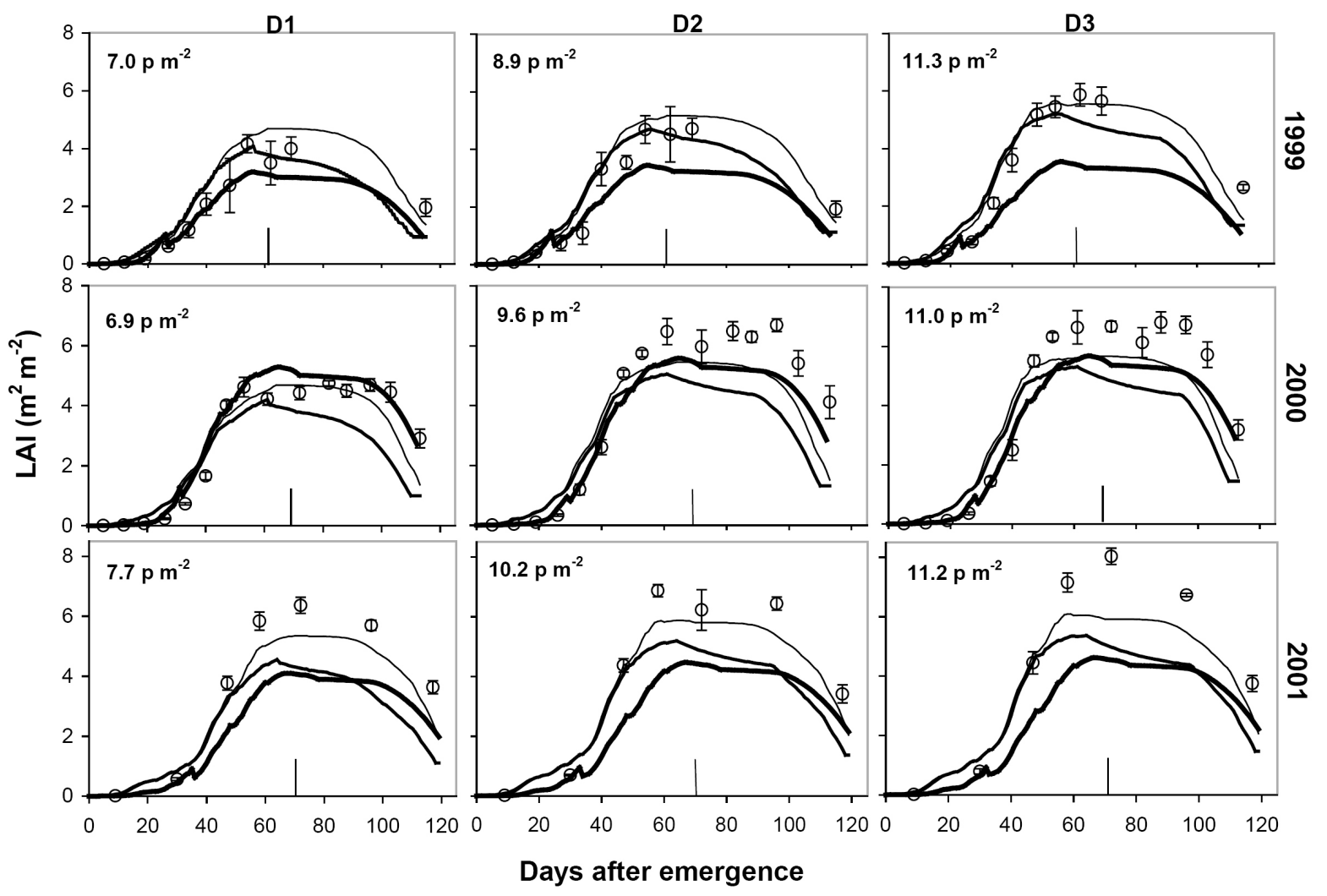

Figure 2. Observed (symbols and error bars = mean and S.E.) LAI of maize and LAI predicted by Hybrid-Maize (fine line), CERES-Maize (medium line), and INTERCOM (thick line) for three plant density treatments (D1, D2, and D3) at Lincoln during 1999-2001. Actual plant densities are shown at upper left of each panel, and vertical bars along the $x$-axis indicate the date of silking.

to measured values than LAI simulated by CERES-Maize or INTERCOM (Table 4). Leaf senescence simulated by CERES-Maize proceeded too quickly, which resulted in a much smaller LAI than observed throughout the grain filling period. Both CERES-Maize and INTERCOM were less consistent in predicting LAI patterns in different years, which is captured by widely varying EF values across years. Substantial underprediction of LAI by these two models was also indicated by significant and large negative AE values in most site-years, particularly in 2001 at Lincoln. In contrast, Hybrid-Maize EF values for LAI were closer to one and the AE values were significant in only one out of four cases - an indication of significant improvement in the prediction of LAI changes during the growing season across plant densities and years.

All three models were capable of predicting early season aboveground dry matter, but they differed in their prediction of biomass after silking (Figure 4, Figure 5, and Figure 6). In general, Hybrid-Maize closely predicted total aboveground dry matter after silking at both sites and at all plant densities, whereas both CERES-Maize and INTERCOM consistently under-predicted dry matter accumulation during the reproductive phase. Modeling efficiencies for total biomass by Hybrid-Maize ranged from 0.97 to 1.00 and the AE was not significant in any of site-years evaluated (Table 4). The short periods of simulated decreases in dry matter accumulation after silking in Hybrid-Maize and CERES-Maize result from the periods of low light intensity or high temperatures when daily requirements for grain filling are not met by net assimilation and translocation of stem carbohydrate reserves makes up the difference (Kiniry et al., 1992). 


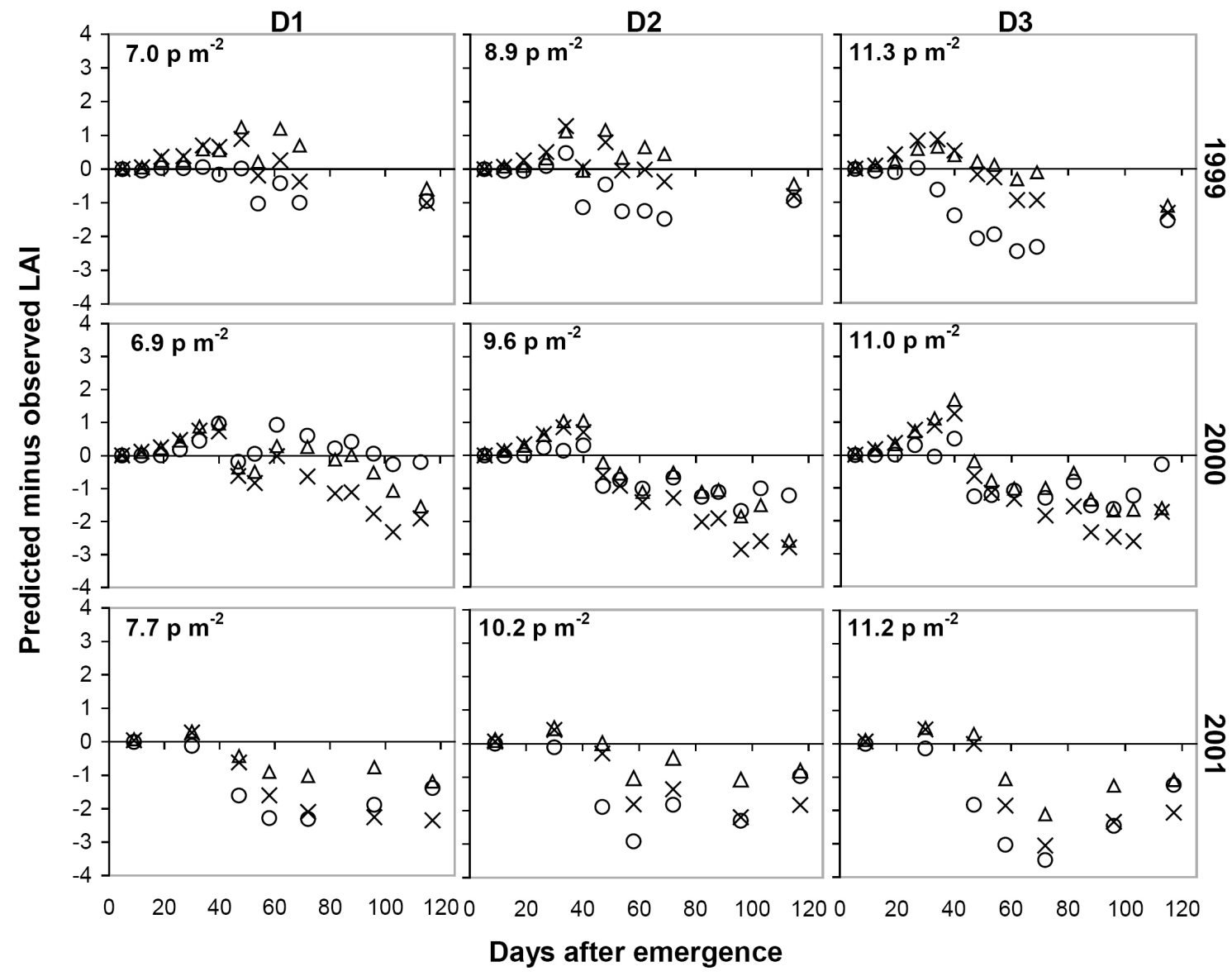

\section{$\Delta$ Hybrid-Maize $\times$ CERES-Maize O INTERCOM}

Figure 3. Deviation of LAI calculated as predicted minus observed values for three plant densities (D1, D2, and D3) at Lincoln during the 1999-2001 cropping seasons.

\subsection{Prediction of grain yield, final stover biomass, and $\mathrm{HI}$}

Observed grain yields in the plant density treatments at Lincoln ranged from 12.5 to 14.0 $\mathrm{Mg} \mathrm{ha}^{-1}$ on an oven-dry basis (Table 5). Grain yields simulated by Hybrid-Maize were -5 to $+12 \%$ of the measured yields across treatments and years. The maximum grain yield measured in the highest-yielding replicate plot may serve as an estimate of the climatic-genetic yield potential at the Lincoln site for the years in which the study was conducted. Maximum plot yields were $14.4 \mathrm{Mg} \mathrm{ha}^{-1}$ in 1999 (in a plot with 11.4 plants $\mathrm{m}^{-2}$ ), $14.0 \mathrm{Mg} \mathrm{ha}^{-1}$ in 2000 (in a plot with 9.8 plants $\mathrm{m}^{-2}$ ), and $14.5 \mathrm{Mg} \mathrm{ha}^{-1}$ in 2001 (in a plot with 11.2 plants $\mathrm{m}^{-2}$ ). These maximum measured yields are in close agreement with the yield potential simulated by Hybrid-Maize of $14.3,14.0$, and $14.1 \mathrm{Mg} \mathrm{ha}^{-1}$ for these same treatment-year combinations (Table 5). The model was also relatively robust in accounting for differences in grain yield associated with plant density in most years. The largest discrepancy between measured and simulated grain yield occurred at the highest plant density in 2000, when measured yield at 11.0 plants $\mathrm{m}^{-2}$ $\left(12.5 \mathrm{Mg} \mathrm{ha}^{-1}\right)$ was smaller than that at a density of 9.6 plants $\mathrm{m}^{-2}\left(13.6 \mathrm{Mg} \mathrm{ha}^{-1}\right)$. In that year, unusually high temperatures in the second half of 

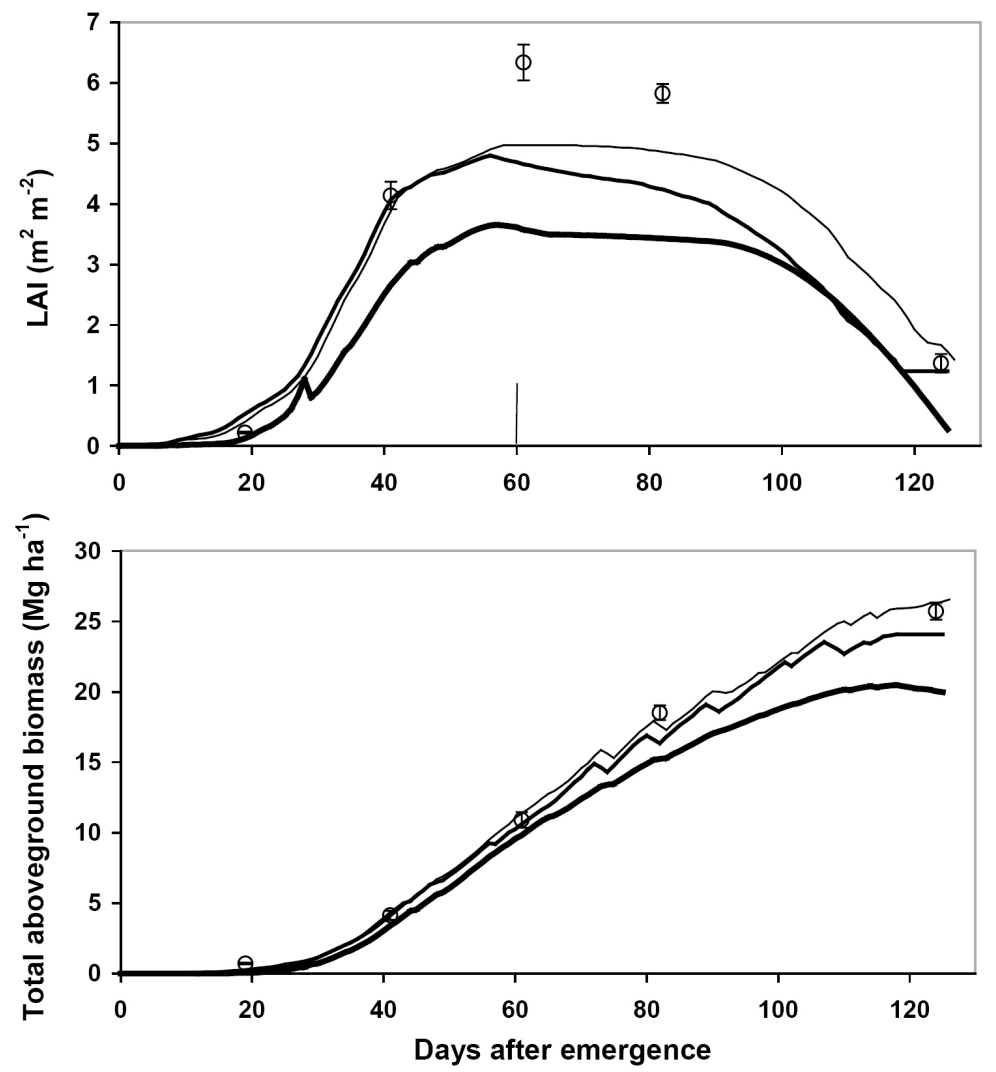

Figure 4. Observed (symbols and error bars = mean and S.E.) and simulated LAI and total aboveground biomass of maize at Manchester, 2002. Simulated values are shown for Hybrid-Maize (thin line), CERES-Maize (medium line), and INTERCOM (thick line) models. The vertical bar along the $x$-axis indicates the date of silking. Plant population was 8.4 plant $\mathrm{m}^{-2}$.

Table 5. Measured (M) and simulated grain and stover yields, and HI by Hybrid-Maize (HM), CERES-Maize (CM), and INTERCOM (I) at Lincoln (1999-2001) and Manchester a

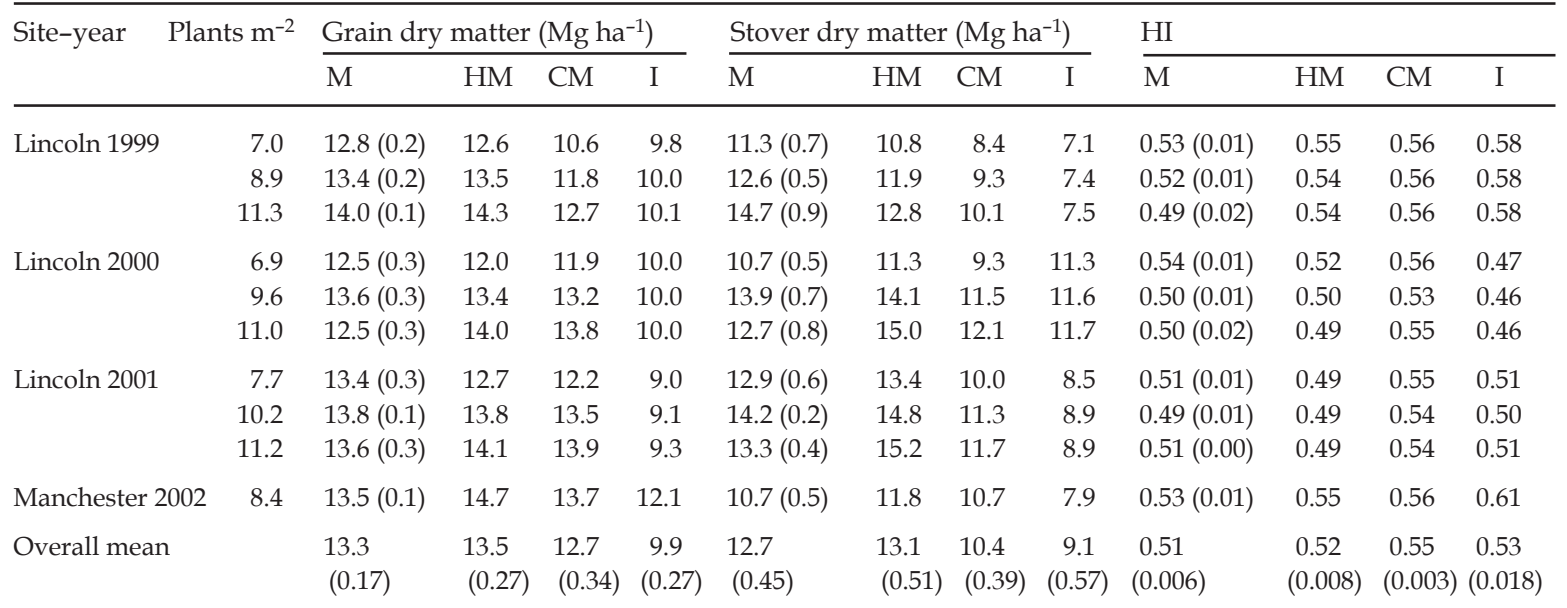



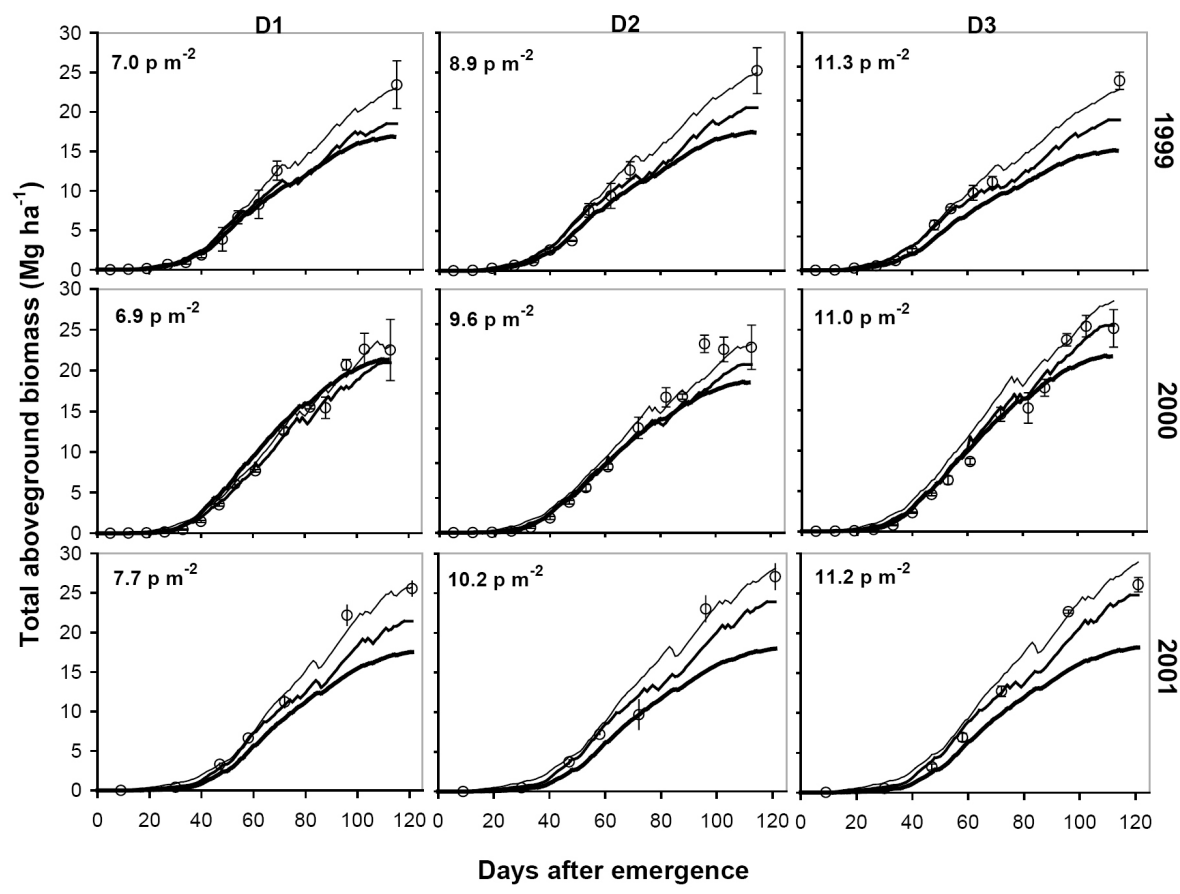

Figure 5. Observed (symbols and error bars = mean and S.E.) total aboveground biomass of maize and biomass predicted by Hybrid-Maize (fine line), CERES-Maize (medium line), and INTERCOM (thick line) models for three plant density treatments (D1, D2, and D3) at Lincoln during the 1999-2001 cropping seasons.

grain filling caused a large decrease in the grain filling period. For example, the grain filling period from silking to physiological maturity was 45 days in 2000 compared to 54-52 in 1999 and 2001 (Table 1), and it appears that Hybrid-Maize was not sensitive to the effects of these high temperatures on grain yield at high plant density.

Predictions of stover yield and HI by HybridMaize were also in reasonable agreement with observed values for most year $\times$ plant density treatment combinations at Lincoln (Table 5). The greatest disagreement between predicted and measured values for stover biomass occurred at the highest plant population in 2000 and 2001 when temperatures during the reproductive phase were well above the 17-year mean for the Lincoln site (Table 2). We suspect that increased respiration losses associated with above-average temperatures during grain filling and high plant density may have reduced biomass, and this interaction is not fully accounted for by HybridMaize. At Manchester, measured grain and stover yields were similar to yields at Lincoln, and the yield potential and HI simulated by HybridMaize was in close agreement with measured values at this site (Table 5).

Yields and HI simulated by Hybrid-Maize were in closer agreement with measured values than simulations by CERES-Maize or INTERCOM when evaluated across all sites, years, and density treatments (Table 5). The improvement in simulation accuracy was especially notable for stover yields, for which simulations by CERESMaize and INTERCOM averaged 18 and 28\% less than measured yields.

\subsection{Sensitivity analyses}

Under growth conditions with minimal stress, total biomass yield simulated by Hybrid-Maize was most sensitive to changes in the initial light use efficiency $(\varepsilon)$ (Figure 7a). Changes in the other plant traits had relatively little effect on total biomass yield. Grain yields were sensitive to changes in potential sink size $\left(G_{2}\right)$, potential grain filling rate $\left(G_{5}\right)$, and $\varepsilon$, all of which increased yield 


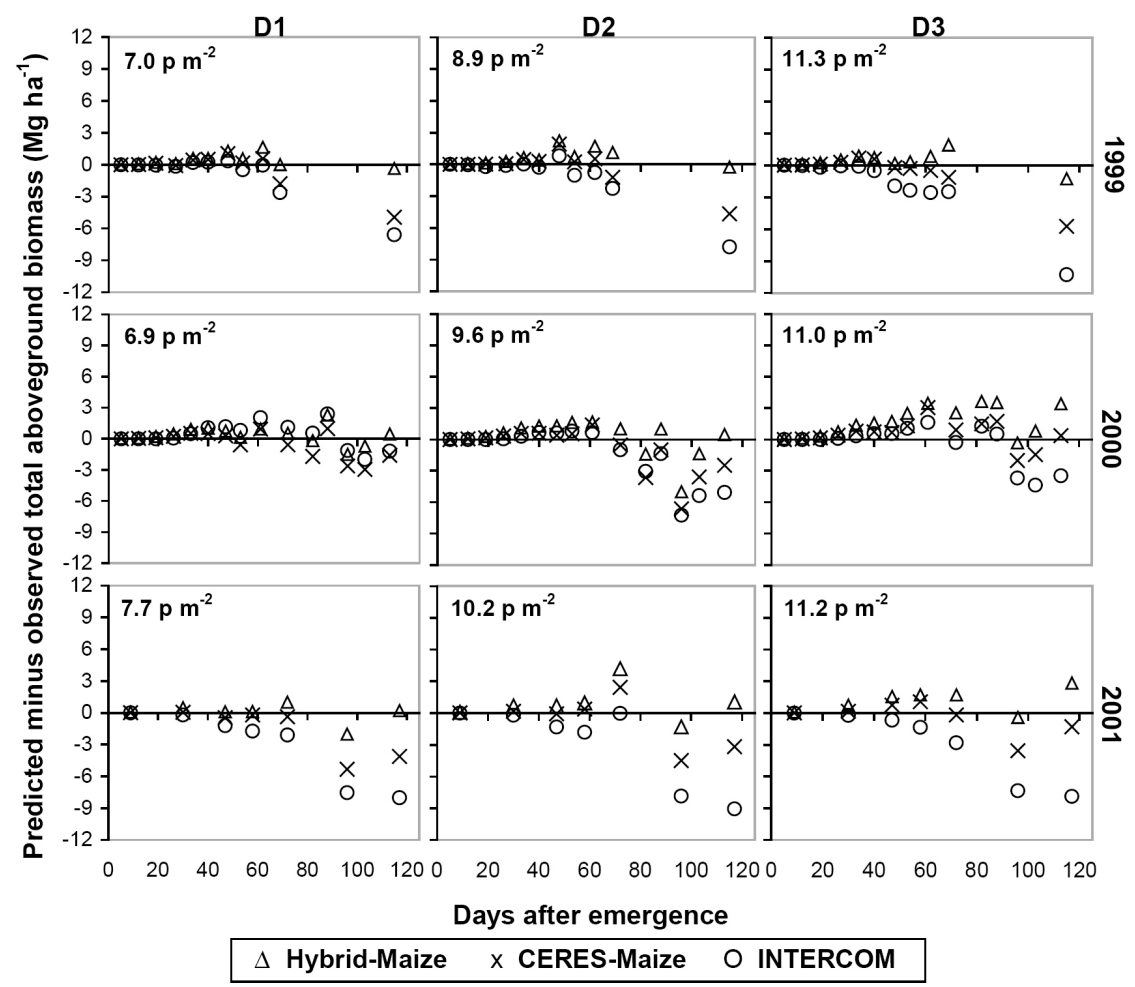

Figure 6. Deviation of total aboveground biomass calculated as predicted minus observed values for three plant densities (D1, D2, and D3) at Lincoln during the 1999-2001 cropping seasons.

with increasing values (Figure $7 \mathrm{~b}$ ). Grain yields were also very sensitive to time of silking, which highlights the importance of accurate specification or estimation of GDD silking to obtain reliable estimates of grain yield from maize simulation models.

The predicted grain yield and aboveground biomass for each of the scenarios in the sensitivity simulations were remarkably stable across the 17 years of climate data. For example, the standard error for the magnitude of difference in total biomass and grain yield simulated over 17 years for each of the modified scenarios in Figure $7(n$ $=84$ ) was less than $1 \%$ in all but three cases. This stability suggests that typical year-to-year variation in climate has relatively small effects on the sensitivity of the parameters tested.

\section{Discussion}

The need for a model that can provide robust simulation of maize yield potential in different environments with a minimum number of loca- tion- or hybrid-specific input parameters was the motivation for developing Hybrid-Maize. Agronomists need such robust crop models to improve the efficiency of research that investigates interactions among crop management options in favorable rainfed and irrigated environments, while crop producers and crop consultants need such models for use in computer-based decision-support tools to improve crop management decisions.

The Hybrid-Maize model builds on the strengths of existing models by combining the crop-specific attributes of CERES-Maize related to phenology and grain filling with explicit photosynthesis and respiration functions from generic crop models such as INTERCOM. Hybrid-Maize also includes additional modifications for several functions based on calibration with experimental data from a field study that produced maize with minimal possible stress conditions that are required to achieve yield potential. When validated against measured yields that approach yield potential levels, Hybrid-Maize simulated seasonal 


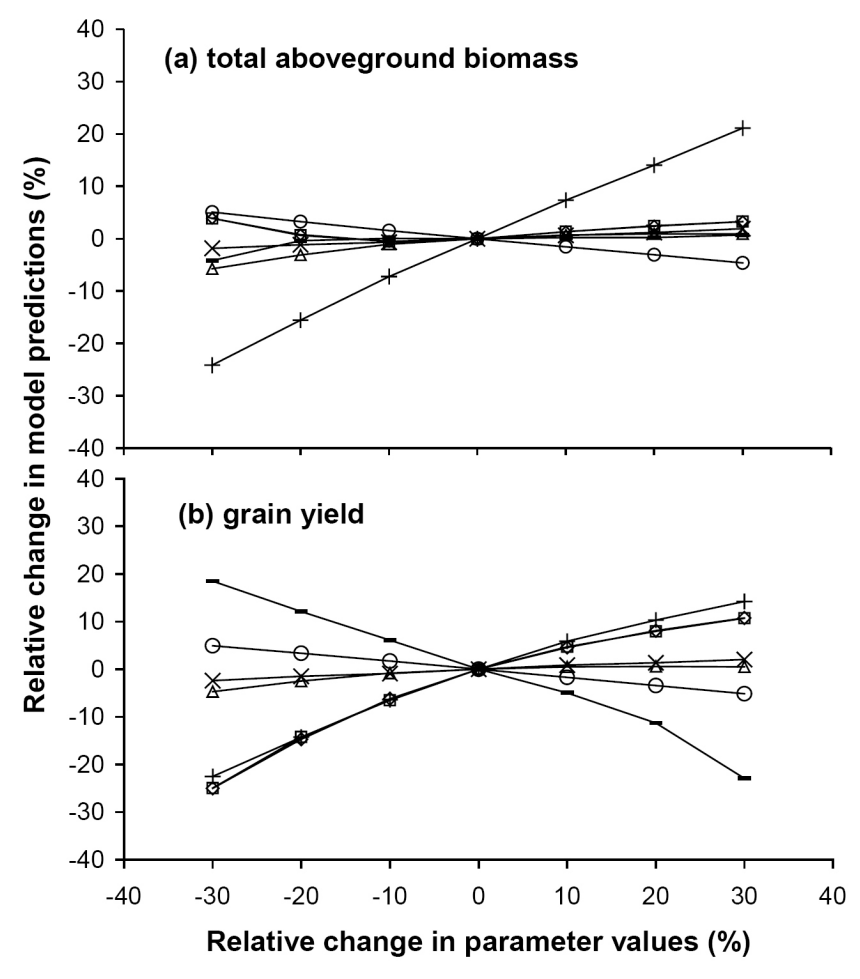

$\diamond$ G2 $\square-$ G5 $\triangle \mathbf{k} \rightarrow$ TE + - MRC - day of silking

Figure 7. Sensitivity analysis of the Hybrid-Maize model based on 17-year mean weather data (1986-2002) at Lincoln. Parameters tested were potential number of kernels per ear $\left(G_{2}\right)$, potential kernel filling rate $\left(G_{5}\right)$, light extinction coefficient $(k), \mathrm{CH}_{2} \mathrm{O}$ translocation efficiency (TE), initial light use efficiency $(\varepsilon)$, mean maintenance respiration coefficient (MRC), and occurrence of silking (day of silking). Except for day of silking, the changes in parameter were $\pm 10, \pm 20$, and $\pm 30 \%$ of the default values listed in Table 4 . The changes for day of silking were $\pm 2, \pm 5$, and \pm 10 days. Each point represents the mean relative change in simulated yields across the 17 -year simulation compared to the simulated yields using the default values. Plant density was set 10 plants $\mathrm{m}^{-2}$ and total GDD from emergence to maturity was set at 1500, which is typical of hybrids used in the field studies.

patterns of LAI and dry matter accumulation, final yields of grain and stover, and HI more accurately than the models from which it was derived. In addition, Hybrid-Maize required fewer cultivar-specific parameters than CERES-Maize, and those parameters are readily available for most commercial varieties.

Accurate prediction of time to silking is crucial for reliable prediction of grain yield, as documented in the sensitivity analysis. A unique feature of Hybrid-Maize is the ability to predict time

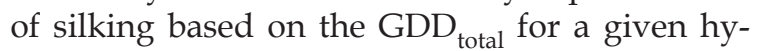
brid, which is likely to improve modeling applications that require forecasting rather than post-season analysis. In contrast, CERES-Maize requires two input parameters $\left(P_{1}\right.$ and $\left.P_{2}\right)$ to pre- dict silking, and both parameters are difficult to measure and are not available for most commercial hybrids. For the four cropping seasons simulated in this study, Hybrid-Maize predicted silking within -3 to +1 days from the actual day of silking while CERES-Maize consistently underpredicted silking by -3 to -6 days.

As a new model, Hybrid-Maize has not been evaluated widely, and it remains to be seen how well it can predict maize yield potential across a greater range of environments than evaluated in our study. Despite the encouraging results from the validations reported here, some discrepancies were apparent between model predictions of yield potential and measured yields under field conditions, particularly at high plant den- 
sity and high temperatures during grain filling. In most cases, the maximum LAI at high plant density was consistently under-predicted by all three models, which indicates that the description of leaf area expansion is still not sufficiently robust when plant densities exceed 9 plants $\mathrm{m}^{-2}$. Because a larger LAI implies greater $\mathrm{C}$ and $\mathrm{N}$ requirements for growth, higher maintenance respiration costs, and a larger $\mathrm{N}$ storage capacity, under-prediction of LAI could potentially affect the accuracy of simulating $\mathrm{C}$ and $\mathrm{N}$ translocation and leaf senescence rates during grain filling.

Hybrid-Maize has not been tested in stress environments where crop growth is limited by water stress, nutrient deficiencies, or both. In such stress environments, under-prediction of LAI would likely have a much larger impact on simulated yields than under the optimal growth conditions of the field experiments used to validate simulations in our study. In Hybrid-Maize, canopy leaf area is simulated by a discontinuous set of equations as in the original CERES-Maize model: one for the period before tassel initiation and another for the period thereafter to silking (Jones and Kiniry, 1986). This approach provides few opportunities to account for genotypic differences in leaf expansion and senescence or to simulate the interactive effects of stresses on these processes (Lizaso et al., 2003a), and such interactions were identified as constraints to accurate prediction of maize growth under stress conditions (Carberry et al., 1989; Keating et al., 1992). We therefore expect that the functions describing leaf expansion during rapid vegetative growth in Hybrid-Maize will need improvement if the model is to be used for simulation of maize growth in stress environments. While Lizaso et al. (2003a) have proposed a more detailed, cultivar-specific leaf area model for maize, it requires three additional cultivar-specific input parameters related to leaf growth and expansion.

All three models showed a lack of agreement between predicted and measured yields at high plant density in years with higher than normal temperatures during grain filling. The interactive effects of plant density and temperature on gross assimilation and assimilate loss from maintenance respiration are apparently not well-accounted for in these models. Addressing this deficiency will require experimental data on res- piration costs of different organs at different development stages under a representative range of temperatures and plant density (van Ittersum et al., 2003). Recent proposed revisions of CERESMaize have focused on genotype and plant density effects on prolificacy, barrenness, and kernel number (Ritchie and Alagarswamy, 2003). Although these modifications improved the prediction of grain yield and yield components, effects on predicted stover biomass and HI were not reported, and obtaining the three additional hybrid-specific genetic coefficients would be a major obstacle for use of such models.

Hybrid-Maize uses a default value of $12.5 \mathrm{~g} \mathrm{CO}_{2} \mathrm{MJ}^{-1}$ PAR from Kropff and van Laar (1993) for the initial light use efficiency $\varepsilon$ (Appendix A). Although the sensitivity analysis identified $\varepsilon$ as a sensitive parameter influencing dry matter production, the range of $\varepsilon$ evaluated in Figure 7 (9-16 $\mathrm{g} \mathrm{CO}_{2} \mathrm{MJ}^{-1}$ ) was far greater than the narrow variation in $\varepsilon$ found in $\mathrm{C} 4$ crops like maize (Ehleringer and Pearcy, 1983; Loomis and Amthor, 1999). Given this lack of variation, prospects for further model improvement through more accurate measurement and specification of $\varepsilon$ appear to be small.

Like CERES-Maize, Hybrid-Maize also simulates root biomass yield and root turnover. This component of Hybrid-Maize has not been validated against experimental data for partitioning of assimilates belowground, and we are not aware of validation studies of this component in CERES-Maize. In fact, such validation represents a substantial experimental effort because assimilate partitioned belowground contributes to root growth, root turnover, root respiration, and root exudation. Hence, a full accounting of belowground root carbon under field conditions is a difficult, and labor-intensive task.

Our longer term goals are to utilize HybridMaize for three purposes: (1) to better understand maize yield potential per se and the effects of climate on yield potential, (2) to improve estimates of $\mathrm{C}$ inputs to soil from maize residues and roots to simulate the $C$ sequestration potential of irrigated maize systems, and (3) to develop a decision-support software tool that includes simulation of maize yield potential to help producers and crop consultants improve crop management decisions regarding hybrid selection, 
date of planting, plant density, and $\mathrm{N}$ fertilizer management in high-yield production environments. While validation across a wider range of environments will be required to provide a more rigorous test of Hybrid-Maize, it appears to have some advantages over existing models in simulating maize yield potential under the favorable growth conditions of the field sites in this study. In addition, Hybrid-Maize gave more accurate simulations of $\mathrm{HI}$ and final stover yield, which are critical parameters for simulating $C$ inputs to soil from crop residues and subsequent $C$ sequestration.

\section{Acknowledgements}

A contribution of the University of Nebraska Agricultural Research Division, Lincoln, NE. Journal Series No. 14167. This research was supported in part by funds provided through the Hatch Act, the Fluid Fertilizer Foundation (FFF), the Foundation for Agronomic Research (funds provided by the Potash \& Phosphate Institute and IMC Global, Inc.), and the Nebraska Corn Board. We thank Darren Binder, Douglas Miller, Gregory Teichmeier, Timothy McAndrew, and Michelle Haddix, for their outstanding technical support to the field management, plant sampling and measurement operations. 


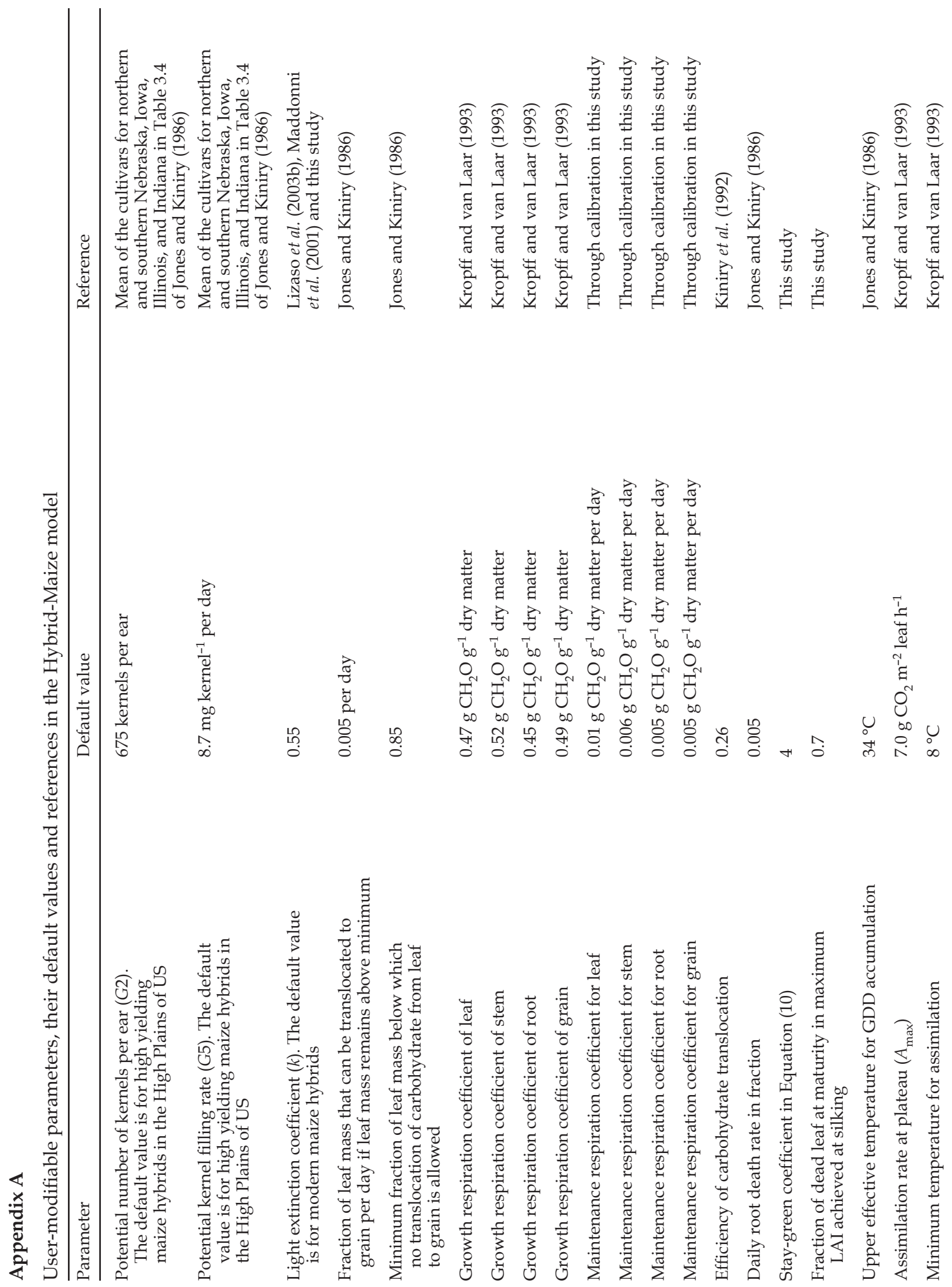




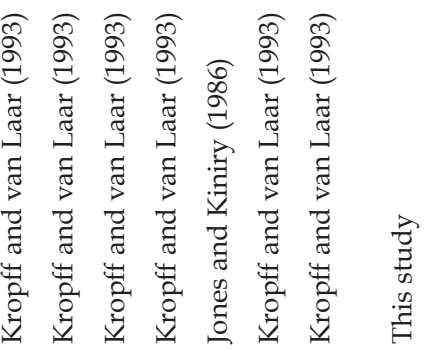




\section{References}

Brisson, N., Gary, C., Justes, E., Roche, R., Mary, B., Ripoche, D., Zimmer, D., Sierra, J., Bertuzzi, P., Burger, P., Bussiere, F., Cabidoche, Y.M., Cellier, P., Debaeke, P., Gaudillere, J.P., Henault, C., Maraux, F., Seguin, B. and Sinoquet, H., 2003. An overview of the crop model STICS. Eur. J. Agron. 18, pp. 309-332.

Carberry, P.S., Muchow, R.C. and McCown, R.L., 1989. Testing the CERES-Maize simulation model in a semi-arid tropical environment. Field Crops Res. 20, pp. 297-315.

Cassman, K.G., Dobermann, A., Walters, D.T., Yang, H.S., 2003. Meeting cereal demand while protecting natural resources and improving environmental quality. Annu. Rev. Environ. Resour. 28, 10.1-10.4410.1146/annurev. energy.28.040202.122858

Earl, H.J. and Tollenaar, M., 1998. Differences among commercial maize (Zea mays L.) hybrids in respiration rates of mature leaves. Field Crops Res. 59, pp. 9-19.

Edmeades, G.O., Bolanos, J., 2001. Issues arising from the use of CERES for tropical maize. In: Directions in Modeling Wheat and Maize for Developing Countries. Proceedings of the Workshop on CIMMYT, El Batan, Mexico, May 4-6, 1998. NRG-GIS Series 01-02. CIMMYT, Mexico, DF, pp. 13-17.

Ehleringer, J. and Pearcy, R.W., 1983. Variation on quantum yield for $\mathrm{CO}_{2}$ uptake among $\mathrm{C} 3$ and $\mathrm{C} 4$ plants. Plant Physiol. 73, pp. 555-559.

Evans, L.T., 1993. Crop Evolution, Adaptation, and Yield. Cambridge University Press, Cambridge, UK.

Fakorede, M.A.B. and Mock, J.J., 1980. Growth analysis of maize variety hybrids obtained from two recurrent selection programmes for grain. New Phytol. 85, pp. 393-408.

Fischer, G., Shah, M., van Velthuizen, H., Nachtergaele, F.O., 2000. Global agro-ecological assessment for agriculture in the 21st century. In: Proceedings of the IIASA, Vienna.

Goudriaan, J., 1986. A simple and fast numerical method for the computation of daily totals of crop photosynthesis. Agric. Forest Meteorol. 38, pp. 249-254.

Goudriaan, J., van Laar, H.H., 1994. Modelling Potential Crop Growth Processes: Textbook with Exercises. Kluwer Academic Publishers, Dordrecht, Boston.
Hammer, G.L., Kropff, M.J., Sinclair, T.R. and Porter, J.R., 2002. Future contributions of crop modeling-from heuristics and supporting decision making to understanding genetic regulation and aiding crop improvement. Eur. J. Agron. 18, pp. 15-31.

Hansen, J.W., 2002. Realizing the potential benefits of climate prediction to agriculture: issues, approaches, challenges. Agric. Syst. 74, pp. 309-330.

Hodges, T., Botner, D., Sakamoto, C. and Hays-Hang, J., 1987. Using the CERES-Maize model to estimate production for the US Cornbelt. Agric. For. Meteorol. 40, pp. 293-303.

Jones, C.A., Kiniry, J.R., 1986. CERES-Maize: A Simulation Model of Maize Growth and Development. Texas A\&M University Press, College Station, TX.

Jones, J.W., Hoogenboom, G., Porter, C.H., Boote, K.J., Batchelor, W.D., Hunt, L.A., Wilkens, P.W., Singh, U., Gijsman, A.J. and Ritchie, J.T., 2003. The DSSAT cropping system model. Eur. J. Agron. 18, pp. 235-265.

Keating, B.A., Wafula, B.M. and Waitiki, J.M., 1992. Development of a modeling capability for maize in semi-arid eastern Kenya. ACIAR Proc. 41, pp. 26-33.

Kiniry, J.R., Tischler, C.R., Rosenthal, W.D. and Gerik, T.J., 1992. Nonstructural carbohydrate utilization by sorghum and maize shaded during grain growth. Crop Sci. 32, pp. 131-137.

Kiniry, J.R., Williams, J.R., Vanderlip, R.L., Atwood, J.D., Reicosky, D.C., Mulliken, J., Cox, W.J., Mascagni, H.J., Hollinger, S.E. and Wiebold, W.J., 1997. Evaluation of two maize models for nine US locations. Agron. J. 89, pp. 421-426.

Kropff, M.J., Vossen, F.J.H., Spitters, C.J.T. and de Groot, W., 1984. Competition between a maize crop and a natural population of Echinochloa Crus-galli (L.). Netherlands J. Agric. Sci. 32, pp. 324-327.

Kropff, M.J., van Laar, H.H., 1993. Modelling CropWeed Interactions. CABI, Wallingford, UK.

Lindquist, J.L., 2001. Performance of INTERCOM for predicting corn-velvetleaf interference across north-central United States. Weed Sci. 49, pp. 195-201.

Liu, W.T.H., Botner, D.M. and Sakamoto, C.M., 1989. Application of CERES-Maize model to yield prediction of a Brazilian maize hybrid. Agric. For. Meteorol. 45, pp. 299-312.

Lizaso, J.I., Batchelor, W.D. and Westgate, M.E., 2003. 
A leaf model to simulate cultivar-specific expansion and senescence of maize leaves. Field Crops Res. 80, pp. 1-17.

Lizaso, J.I., Batchelor, W.D., Westgate, M.E. and Echarte, L., 2003. Enhancing the ability of CERES-Maize to compute light capture. Agric. Syst. 76, pp. 293-311.

Loomis, R.S. and Amthor, J.S., 1999. Yield potential, plant assimilatory capacity, and metabolic efficiencies. Crop Sci. 39, pp. 1584-1596.

Maddonni, G.A., Otegui, M.E. and Cirilo, A.G., 2001. Plant population density, row spacing and hybrid effects on maize canopy architecture and light attenuation. Field Crops Res. 71, pp. 183-193.

Monteith, J.L., 1969. Light interception and radiative exchange in crop stands. In: Eastin, J.D. (Ed.), Physiological Aspects of Crop Yield. ASA, Madison, WI, pp. 89-111.

Muchow, R.C., Sinclair, T.R. and Bennett, J.M., 1990. Temperature and solar radiation effects on potential maize yields across locations. Agron. J. 82, pp. 338-342.

Murrell, T.S. and Childs, F.R., 2000. Redefining corn yield potential. Better Crops 84, pp. 33-37.

NCGA, 2003. National Corn Growers AssociationCorn Yield Contest. http://www.ncga.com// 02profits/CYC/main/index.html

Nouna, B.B., Katerji, N. and Mastrorilli, M., 2000. Using the CERES-Maize model in a semi-arid Mediterranean environment. Evaluation of model performance. Eur. J. Agron. 13, pp. 309-322.

Pang, X.P., Letey, J. and Wu, L., 1997. Yield and nitrogen uptake prediction by CERES-Maize model under semiarid conditions. Soil Sci. Soc. Am. J. 61, pp. 254-256.

Penning de Vries, F.W.T., Jansen, D.M., ten Berge, H.F.M., Bakema, A., 1989. Simulation of ecophysiological processes of growth in several annual crops. Simulation Monographs 29. PUDOC, Wageningen.

Pioneer Hi-Bred, I., 2001. Crop Notes 2001-2002. Pioneer Hi-Bred, Inc., A DuPont Company, Johnston, IA.

Rajcan, I. and Tollenaar, M., 1999. Source:sink ratio and leaf senescence in maize. II. Nitrogen metabolism during grain filling. Field Crops Res. 60, pp. 255-265.
Ritchie, J.T. and Alagarswamy, G., 2003. Model concepts to express genetic differences in maize yield components. Agron. J. 95, pp. 4-9.

Roman, P.E., Welch, S.M. and Vanderlip, R.L., 2000. Comparing genetic coefficient estimation methods using the CERES-maize model. Agric. Syst. 65, pp. 29-41.

Saini, H.S. and Westgate, M.E., 2000. Reproductive development in grain crops during drought. Adv. Agron. 68, pp. 59-96.

Smith, P., Smith, J.U., Powlson, D.S., Mcgill, W.B., Arah, J.R.M., Chertov, O.G., Coleman, K., Franko, U., Frolking, S., Jenkinson, D.S., Jensen, L.S., Kelly, R.H., Gunnewiek, H., Komarov, A.S., Li, C., Molina, J.A.E., Mueller, T., Parton, W.J., Thornley, J.H.M. and Whitmore, A.P., 1997. A comparison of the performance of nine soil organic matter models using datasets from seven long-term experiments. Geoderma 81, pp. 153-225.

Soil Survey Staff, 1999. Soil taxonomy: a basic system of soil classification for making and interpreting soil surveys. USDA-NRCS, Washington, DC.

Stöckle, C., Donatelli, M. and Nelson, R., 2003. CropSyst, a cropping systems simulation model. Eur. J. Agron. 18, pp. 289-307.

Van Diepen, C.A., Wolf, J., van Keulen, H. and Rappoldt, C., 1989. WOFOST: a simulation model of crop production. Soil Use Manage. 5, pp. 16-24.

van Ittersum, M.K., Leffelaar, P.A., van Keulen, H., Kropff, M.J., Bastiaans, L. and Goudriaan, J., 2003. On approaches an applications of the Wageningen crop models. Eur. J. Agron. 18, pp. 201-234.

Wilson, D.R., Muchow, R.C. and Murgatroyd, C.J., 1995. Model analysis of temperature and solar radiation limitations to maize potential productivity in cool climate. Field Crops Res. 43, pp. 1-18.

Xie, Y., Kiniry, J.R., Nedbalek, V. and Rosenthal, W.D., 2001. Maize and sorghum simulations with CERES-Maize, SORKAM, and ALMANAC under water-limiting conditions. Agron. J. 93, pp. 1148-1155. 